\title{
Über die Porphyrinsynthese in der Leberzellkultur unter der Einwirkung von Pharmaka und Steroiden ${ }^{1}$ )
}

\author{
Von M. Doss \\ Aus dem Hygiene-Institut der Universität Marburg/Labn (Direktor: Prof. Dr. R. Siegert)
}

(Eingegangen am 27. Dezember 1968)

\author{
Herrn Prof. Dr. Brugsch zum 60. Geburtstag gewidmet
}

Es wird über die Wirkung verschiedener Pharmaka und Steroide auf die Porphyrinsynthesc in primären Hühnerembryo-Leberzellkulturen berichtet:

1. Zunächst wird ein Verfahren zum Anlegen primärer Hühnerembryo-Leberzellkulturen beschrieben. Die Isolierung der Porphyrine erfolgte aus der gefriergetrockneten Zellkultur dünnschichtchromatographisch als Methylester, die nach Elution spektrophotometrisch als $\mathrm{Cu}$-Chelat-Komplexe bestimmt wurden.

2. Pharmaka verschiedener chemischer Gruppen sowie Steroidmetabolite aus dem Stoffwechsel der Sexualhormone führten in den Leberzellkulturen zu einer Erhöhung der Porphyrinsynthese, wobei vorwiegend Protoporphyrin entstand.

3. Versuche mit Meprobamat und Ätiocholanolon zeigten, daß der Anstieg des Proto- und Koproporphyrins von der Konzentration der zugesetzten Substanz abhängig ist. Geschädigtc Zellen synthetisierten nur bis zum Koproporphyrin.

4. Der die Porphyrinsynthese stimulierende Prozeß wurde einerseits durch Protohämin und andererseits durch Actinomycin D, Mitomycin $C$ und Puromycin unterdrückt. Demzufolge wird die Steigerung der Porphyrinsynthese durch Pharmaka und Steroide auf eine Derepression der $\delta$-Aminolävulinsäure-Synthetase, des limitierenden Enzyms der Hämbiosynthese, zurückgeführt.

5. Aus zugesetzter $\delta$-Aminolävulinsäure wurden unter der Einwirkung von $p$-Hydroxy-phenylbutazon mehr Uroporphyrin und von Methyprylon mehr Koproporphyrin synthetisiert. Inhibitoren der Nucleinsäure- und Proteinsynthese beeinflußten diesen Effekt der Pharmaka auf die Porphyrinsynthese aus $\delta$-Aminolävulinsäure nicht.

6. In mit stark induzierend wirkenden Substanzen beschickten Kulturen wurden simultan mit dem Anstieg des Protoporphyrins ein höherer Protohämingehalt durch differenzspektrophotometrische Analysen gefunden. Die Leberzellen, die in einem mit $\delta$-Aminolävulinsäure oder Protoporphyrin supplementierten Medium inkubiert wurden, enthielten mehr Protohämin als Kulturen ohne diese Zusätze. Daraus wird geschlossen, daß die in Kultur inkubierten Leberzellen Protohäm synthetisieren.

7. Die Ergebnisse der pharmaka- und steroidinduzierten Porphyrinsynthese in vitro werden zur Pathogenese der genetisch determinierten hepatischen Porphyrien des Menschen in Beziehung gesetzt. Wahrscheinlich ist eine Störung der molekularen Kontrollmechanismen der Hämsynthese bei diesen Krankheiten von ursächlicher Bedeutung. Die durch Pharmaka und Steroide ausgelöste Manifestation ist sekundär und basiert auf der in vivo und in vitro nachgewiesenen Wirkung der Substanzen auf die Porphyrinsynthese.

8. Die Induktion der Porphyrinsynthese ist wie die Induktion arzneimittelabbauender Enzyme ein unspezifischer Prozeß. Beiden Prozessen gemeinsame Befunde werden herausgestellt und beide Prozesse verbindende funktionelle Mechanismen besprochen.

\section{Porpbyrin synthesis in liver cell culture and the effect of drugs and steroids}

Results are reported on the action of various pharmaceutical substances and steroids on porphyrin synthesis in primary chicken embryo liver cell cultures:

1. First a method is described for the initiation of primary chicken embryo liver cell cultures. The porphyrins were isolated from freezedried cell cultures by thin layer chromatography of their methyl esters. The methyl esters were then eluted and converted into the $\mathrm{Cu}$ chelate complexes, which were determined spectrophotometrically.

2. Several drugs of various classes and steroid metabolites of the sex hormones caused an increase in the synthesis of porphyrins in liver cell cultures and the main product was protoporphyrin.

3. Experiments with meprobamate and aetiocholanolone showed that the increase of copro- and protoporphyrin is dependent on the concentration of the added substance. Damaged cells can only achieve the synthesis as far as coproporphyrin.

4. The stimulation of porphyrin synthesis was suppressed by protohaem and by actinomycin $D$, mitomycin $C$ and puromycin. From this it is concluded that the stimulation of porphyrin synthesis by pharmaceuticals and steroids is the result of the derepression of $\delta$-aminolaevulinic acid synthetase, the limiting enzyme of haem biosynthesis.

5. In the presence of $p$-hydroxy-phenylbutazone, more uroporphyrin was synthesised from added $\delta$-amino-laevulinic acid, and in the presence of methyprylone more coproporphyrin was synthesised; this phenomenon was not affected by the inhibition of nucleic acid and protein synthesis.

6. In cultures containing strongly inducing substances, differential spectrophotometric analysis showed that the increase in protoporphyrin was accompanied by a simultaneous increase in protohaemin. Liver cells incubated in a medium supplemented with $\delta$-amino-laevulinic acid or protoporphyrin contained more protohacmin than cultures without these additions. From this it is concluded that the cultured liver cells synthesise protohaem:

7. The results from the induction of porphyrin synthesis by certain drugs and steroids in vitro are discussed in relationship to the pathogenesis of genetically determined hepatic porphyrias in humans. These diseases are probably caused by the disturbance of the molecular control mechanisms of haem synthesis. The condition induced by drugs and steroids is secondary and due to the action of these substances on porphyrin synthesis, which has been demonstrated in vivo and in vitro.

8. The induction of porphyrin synthesis is unspecific, resembling in this respect the induction of enzymes that degrade pharmaceutical substances. Findings common to both processes are presented and a unifying mechanism for both processes is discussed.

1) Mit Unterstützung der Deutschen Forschungsgemeinschaft. 
Zahlreiche Fremdstoffe, die größtenteils als Pharmaka in der klinischen Medizin Verwendung finden, steigern die Porphyrinbiosynthese in primären HühnerembryoLeberzellkulturen (1). Der Befund wurde in Anlehnung an die Hypothese über die Gen-abhängigen Mechanismen der Protein-Enzym-Synthese und ihrer Kontrolle erklärt, wie sie JACOB und MONOD (2) aufgestellt haben und von LwOFF (3) zusammenfassend beschrieben worden sind. Das Vorkommen der beiden, heute als Arbeitshypothesen relevanten Regelmechanismen, der zellulären („genetischen") und der „epigenetischen" $(4,5)$ Hemmung für den Reaktionsablauf der Hämsynthese, hat LASCELles (6) an dem photosynthetischen Bakterium Rhodopseudomonas sphaeroides festgestellt. In der Leberzelle ist nach den Ergebnissen von GrANICK (1) nur der Regulationsmechanismus einer Repression vorhanden, wobei nach Potrer (4) „the term 'repression' has been used to describe feedback at the level of enzyme formation and 'negative feedback' has been used in a restricted sense to mean only the inhibition of enzyme activity". Die Kontrolle vollzieht sich bei photosynthetischen Bakterien $(6,7)$ und bei dem aeroben Keim Acbromobacter metalcaligenes (8) sowie in Proerythroblasten (9) und in der Leberzelle, sowohl in der des Hühnerembryos (1) als auch des Menschen (10), an der Bildung des ersten Enzyms der Hämbiosynthese, der $\delta$-Aminolävulinsäure-Synthetase, die somit als Schlüsselenzym für diese Stoffwechselkette fungiert.

Die Fähigkeit zur Derepression der Porphyrinsynthese ist allerdings keine spezifische Eigenschaft der Pharmaka und anderer chemischer Fremdstoffe, sondern sie wird ebenfalls durch eine Anzahl stereoisomerer biologischer Steroidmetabolite der Sexualhormone, die über eine cis-Konfiguration der $\mathrm{A}: \mathrm{B}$-Ringe (5 $\beta$-H-Typ) verfügen, ausgelöst $(11,12)$. Diese Steroide induzieren die Porphyrinsynthese aber nicht nur in der Leberzelle. In Kulturen erythroider Zellen aus Hühnerblastoderm konnte die Häm- und Hämoglobinsynthese durch dieselben physiologischen Steroide, welche die Porphyrinsynthese in der Leberzelle steigern, stimuliert werden (13). Die Autoren (13) stellten die Arbeitshypothese auf, daß Steroide physiologischerweise in die Kontrollmechanismen der Hämsynthese sämtlicher Zellen eingreifen und den Repressionsvorgang durch eine Kompetition mit dem Corepressor steuern.

Neben der $\delta$-Aminolävulinsäure-Synthetase kommen als weitere regulative Enzyme für die Hämsynthese ein induzierbares Isoenzym der Succinyl-CoA-Synthetase ${ }^{2}$ ) in der Leberzelle (14) und bei Rhodopseudomonas sphaeroides auch die $\delta$-Aminolävulinsäure-Dehydratase ${ }^{2}$ ), deren mit der $\delta$-Aminolävulinsäure-Synthetase koordinierte Repression durch Hämin erfolgt (15), in Betracht. Die $\delta$-Aminolävulinsäure-Synthetase wird außerdem sowohl

2) Env'me: Succinyl-CoA-Synthetase (EC 6.2.1.4), $\delta$-Aminolävulinsäure-Dehydratase (EC 4.2.1.24), Ferrochelatase (EC 4.99. 1.1); Uroporphyrinogen-Decarboxylase = UroporphyrinogenIII-Carboxy-lyase (EC 4.1.1.37); Tryptophan-Pyrrolase (EC 1.13.1.12). bei Rhodopseudomonas sphaeroides (16) als auch in Suspensionen intakter und lysierter Kaninchen-Retikulocyten (17) auf der Stufe des epigenetischen feedbackSystems durch Hämin gehemmt. Eine solche direkte Hemmung der $\delta$-Aminolävulinsäure-Synthetase durch Häm wurde weiterhin an isolierten Mitochondrien von Kaninchen-Retikulocyten (18) und in kinetischen Studien einer mitochondrialen. Präparation des Enzyms aus Hühner-Retikulocyten (19) gefunden. Ein analoger Wirkungsmechanismus von Häm auf das nächste Enzym der Porphyrinsynthese, die $\delta$-Aminolävulinsäure-Dehydratase, wurde an den Erythrocyten des Menschen beobachtet (20). Nach Untersuchungen an den Knochenmarkzellen des Menschen wird der letzte Schritt der Hämsynthese ebenfalls durch einen negativen „feed-

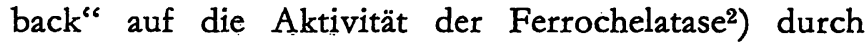
Häm kontrolliert (21).

Bei den Untersuchungen über die Porphyrinsynthese in der Leberzelle blieben die Fragen offen, welche Porphyrine von der Synthesesteigerung betroffen werden, und wie sich der Anstieg der einzelnen Porphyrine quantitativ vollzieht. Als biologisches Versuchssystem wurde die primäre Zellkultur aus Hühnerembryoleber gewählt. Mit der Entwicklung eines dünnschichtchromatographischen Verfahrens zur Differenzierung sämtlicher, im biologischen Material vorkommenden Porphyrine (22), verbunden mit einer empfirídichen spektrophotometrischen Bestimmung (23), wurde es möglich, die Biosynthese der individuellen Porphyrine in kleinsten Mengen zu verfolgen. Über einige Ergebnisse dieser Experimente an Leberzellkulturen wurde bereits referiert $(24,25)$. In dieser Arbeit wird neben einer Beschreibung der Methoden über die Wirkung einiger Pharmaka und Steroide auf die Porphyrinsynthese in der primären Zellkultur von HühnerembryoLeberzellen berichtet.

\section{Material und Methoden}

Chemikalien

Porphyrinvergleichssubstanzen wurden als Methylester nach eigenen Verfahren aus porphyrischem Urin oder proliferierenden Zellsuspensionen von Acbromobacter metalcaligenes, die Porphyrine aus zugesetzter $\delta$-Aminolävulinsäure $1 \mathrm{mu}$ (Fluka AG., Buchs, Schweiz) synthetisierten, isoliert. Protohämin-dimethylester wurde aus Häminchlorid gewonnen (26).

Diallylbarbitursäure, Chloroquindiphosphat und Diäthyl-1,4dihydro-2,4,6-trimethylpyridin-3,5-dicarboxylat (3,5-Dicarbäthoxy-1,4-dihydrocollidin, DDC; K \& K Laboratories, Inc., Plainview, N. Y., Hollywood) wurden über Serva (Heidelberg) bezogen. Die übrigen Pharmaka stellte die pharmazeutische Industrie in Form von Reinsubstanzen zur Verfügung. Steroide wurden teilweise von Schering AG. (Berlin) erhalten und von E. Merck AG. (Dar:nstadt) und Fluka AG. (Buchs) bezogen.

Die Medien zum Anlegen der Zellkulturen (27) stellte die virologische Abteilung (Doz. Dr. F. LehmanN-GrubE) des HygieneInstitutes zur Verfügung.

Zur Dünnschichtchromatographie verwendeten wir KieselgelFertigplatten mit einer Schichtdicke von 0,25 mm (E. Merck). Die spektrophotometrischen Analysen wurden mit einem Spektralphotometer DB-G der Firma Beckman (München) durchgeführt.

Hühnerembryo-Leberzellkulturen

Die Zellkulturen wurden nach den von LeHManN-GruBE (27) angegebenen Richtlinien angelegt. Die Lebcr 17 Tage alter 
Hühnerembryonen wurde steril entnommen, mit Hilfe scherenartig gekrcuzter Skalpelle in physiologisch balancierter SalzGlucose-Lösung (BSL) von HANKs $(28)$ bei $+4^{\circ}$ so weit zerklcincrt, daß einc breiartige Gewebssuspension entstand, die man nach zweimaligem Waschen in BSL $\left(+4^{\circ}\right)$ in einem Trypsinicrungskolben (Abb. s. 1. c. 27) überführte. Das Lebergewebe wurde nun mit cincr auf $37^{\circ}$ gebrachten 0,2proz. Trypsinlösung (29) in BSL unter langsamem Rühren dcr Suspension auf einem Magnetrührer zu Einzelzcllen zerlegt. Nach je 10 Min. wurde die Suspension mit den freigesetzten Zellen über einen Seitenarm des Kolbens durch einen mit fünf Lagèn Gaze belcgten Trichter in cinc Sammelfasche filtriert und bei $+4^{\circ}$ gehalten. Mit frischer Trypsinlösung wurde die Auflösung der im Kolben zurückgebliebenen Gewebeteilchen fortgesetzt. Die Dauer der Trypsinierung betrug etwa cine Std. Um aus 40 Lebern Einzelzellen zu erhalten, benötigte man etwa 1,5/ Trypsinlösung. Anschlicßend wurden die Zcllen sedimentiert $\left(+4^{\circ}, 50 \mathrm{~g}, 3 \mathrm{Min}\right.$.) und nach Absaugen des Uberstandes in 20 bis $30 \mathrm{~m} /$ Wuchsmedium, das 5proz. $\mathrm{NaHCO}_{3}$-Lösung enthielt, resuspendicrt. Nach Bestimmung der Zellzahl durch Auszählen der Leberzellen eines mit Kristallviolettlösung (cf. 27) gefärbten Aliquots $(0,5 \mathrm{~m} / \mathrm{Zcll}$ suspension $+4,5 \mathrm{~m} /$ Kristallviolcttlösung; Anfärbung der Zellkerne) in einer Neubaucr-Zählkammer wurde die Suspension, die ncben Lcberzellen auch cinige Erythrocyten und Zelltrümmer enthiclt, zu einer Dichte von $10^{6}$ Lebcrzellen $/ \mathrm{m} / \mathrm{mit}$ dem Wuchsmedium verdünnt. Das Wuchsmedium bestand aus EAGLes Medium (30), supplementiert mit 0,5\% Lactalbumin-Hydrolysat (27) und 10\% Kälberserum. Je eine Mega-Einhcit Penicillin und $1 \mathrm{~g}$ Streptomycin wurden auf $500 \mathrm{~m} /$ Medium hinzugefügt.

Zur Kultivierung gelangten je $5 \mathrm{~m} /$ Zellsuspension ciner Dichte von $10^{6}$ Zellen $/ \mathrm{m} /$ Wuchsmedium in kleinen Petrischalen $(60 \times$ $15 \mathrm{~mm}$ ). Aus 40 Lebern konnten ctwa 150 Kulturen gewonnen wcrden. Die Anzüchtung der Lebcrzellkulturen wurde im Wassermantclbrutschrank bei $37-37,5^{\circ}$ in ciner Atmosphärc von $5 \%$ $\mathrm{CO}_{2}$ in Luft durchgeführt. Bcreits nach wenigen Stunden befand sich der überwiegende Teil von J.ebcrzellen am Glas und bildete monolayer-Kolonien. Einen homogenen und lückenlosen Zellrasen entwickelten die Kulturen jedoch auch zu einem späteren Zeitpunkt selten. Die Kulturen wurden meistens nicht länger als $50 \mathrm{Stdn}$. inkubicrt, wobei man das Medium mit demselben Wuchsmedium in der Regel nach 20 bis 24 Stdn. wechselte. Nach Beendigung der Kultivicrung wurden die Zellen mit einem schmalen Gummischaber vom Glas gelöst. Die Zellsuspension überführtc man in ein Veresterungsgefäß $(180 \times 16 \mathrm{~mm}$, NS 14,5), in dem sie zur Gefriertrocknung schräg eingefroren wurden. Für eine getrennte Aufarbeitung von Zcllen und Medium wurden die Zellen vorhcr sedimentiert $(2000 \mathrm{~g}, 5 \mathrm{Min}$.) und Zellen sowic Medium separat lyophilisiert.

Darstellung und Extraktion der Porphyrinmethylester Die Porphyrine und das Hämin wurden in den gefriergetrockneten Proben mit je $5 \mathrm{~m} /$ Methanol- $\mathrm{H}_{2} \mathrm{SO}_{4}(95: 5 \mathrm{v} / \mathrm{v})$ in $10 \mathrm{Stdn}$. be Raumtemperatur verestert und als Methylester (ME) mit Chloroform extrahicrt, wobei sich das folgende Vorgehen bewährte: Dem Methanol-Schwcfelsäuregemisch wurden $2 \mathrm{~m} / \mathrm{CHCl}_{3}$ hinzugefügt. Dann filtrierte man die Mischung durch ein Faltenfilter $(\varnothing 9 \mathrm{~cm})$ in ein Extraktionsgefäß $(190 \times 20 \mathrm{~mm}$, NS 14,5$)$, spülte das Veresterungsgefäß $\beta$ mit $5 \mathrm{~m} /$ Chloroform-Methanol $(4: 1, v / v)$ nach und überführte diese ebenfalls durch das Filter in das Extraktionsgefäß. Nach Zusatz von $15 \mathrm{~m} l$ dest. Wasser wurde das Gefäß 3 Min. geschüttelt. Nachdem einc vollständige Phasentrennung eingetreten war, wurde die Chloroformphase mit einem zu einer Kapillare ausgezogenen Glasrohr abgezogen und in ein Sammelgefäß $(180 \times 16 \mathrm{~mm}$, NS 14,5) überführt. Darauf folgten cine Extraktion mit je $5 \mathrm{~m} /$ und noch zwei Extraktionen mit je $3 \mathrm{~m} /$ Chloroform, so daß mindestens vier Extraktionen durchgeführt wurden, wobei die Porphyrin-ME quantitativ in die Chloroformphase übergegangen waren. Bei geringen Porphyrinkonzentrationen ist dex Nachweis der Rotfluoreszenz der Chloroformextrakte im UV-Licht $(366 \mathrm{~nm})$ nicht möglich. Bei- Porphyrinkonzentrationen, die bcreits im UV-Licht nachgewiesen werden können, wurden Intensität und Anzahl der Extraktionen vom
Fluoreszenznachweis abhängig gemacht. Bei den Kulturen, denen $\delta$-Aminolävulinsäure zugesetzt worden war, kam man in der Regel mit fünf bis sechs Extraktionen aus. Dic beim Anziehen des Chloroforms aus dem Extraktionsgefäß mitgenommenen geringen Volumina der wäßr. oberen Phase wurden mit einer spitzen Kapillare soweit wic möglich vollständig entfernt, che man die organische Phase mit möglichst wenig (ein bis zwci Spatelspitzen) $\mathrm{Na}_{2} \mathrm{SO}_{4}$ trocknete. Fünf Min. nach Zugabe des $\mathrm{Na}_{2} \mathrm{SO}_{4}$ wurde der Chloroformextrakt durch ein Faltenfilter $(\varnothing 9 \mathrm{~cm})$, in das zusätzlich etwas $\mathrm{Na}_{2} \mathrm{SO}_{4}$ gegeben wurde, in ein $25-\mathrm{m} /-\mathrm{Spitz}$ kölbchen filtriert und eingedampft. Das Sammelgefäß wurde zweimal mit $5 \mathrm{~m} /$ warmem Chloroform $\left(37^{\circ}\right)$ nachgespült, dic ebenfalls in das gleiche Kölbchen filtriert und eingedampft wurden. Zusatzversuche ergaben, daß die Ausbeuteverluste bei diescm Extraktionsverfahren unter 5\% licgen.

\section{Dünnschichtchromatographie}

Der mit etwa $0,25 \mathrm{~m} / \mathrm{CHCl}_{3}$ wieder gelöstc Tetrapyrrol-MEExtrakt ciner Probe wurde auf eine DC-Kiesclgcl-Fertigplattc mit einer Schichtdicke von $0,25 \mathrm{~mm}$ in Form cincs ctwa $3 \mathrm{~cm}$ breiten Streifens quantitativ aufgetragen. So konnten auf ciner $20 \times 20 \mathrm{~cm}$ großen Platte, dic in der Mitte Vergleichssubstanzen führte, vicr Proben appliziert werden.

Die zur Porphyrinchromatographic verwendeten KicsclgelPlatten waren nacheinander in den Lösungsmittelsystemen Chloroform-Methanol $(2: 1, \mathrm{v} / \mathrm{v})$ und Benzol-Essigsäurcäthylester (4:1, $\mathrm{v} / \mathrm{v}$ ) bis an den oberen Plattenrand vorgelaufen, um Verunreinigungen zu climinieren, und sind anschlicßend wicder aktiviert worden $\left(90^{\circ}, 30 \mathrm{Min}\right.$.). Dieses Vorlaufen der Platten bewährtc sich, um cine photometrisch leerwertfreic Analyse der vom Adsorbens cluicrten ME zu erhalten. Das Chromatogramm wurde nun in den folgenden Lösungsmittelsystemen stufenweise entwickelt (Abb. 1):

a) Chloroform-Methanol (130:20, v/v), zwcimal $2 \mathrm{~cm}$, danach vollständige Lufttrocknung. An der Lösungsmittclfront Bildung der neuen Startzone der Porphyrin-ME.

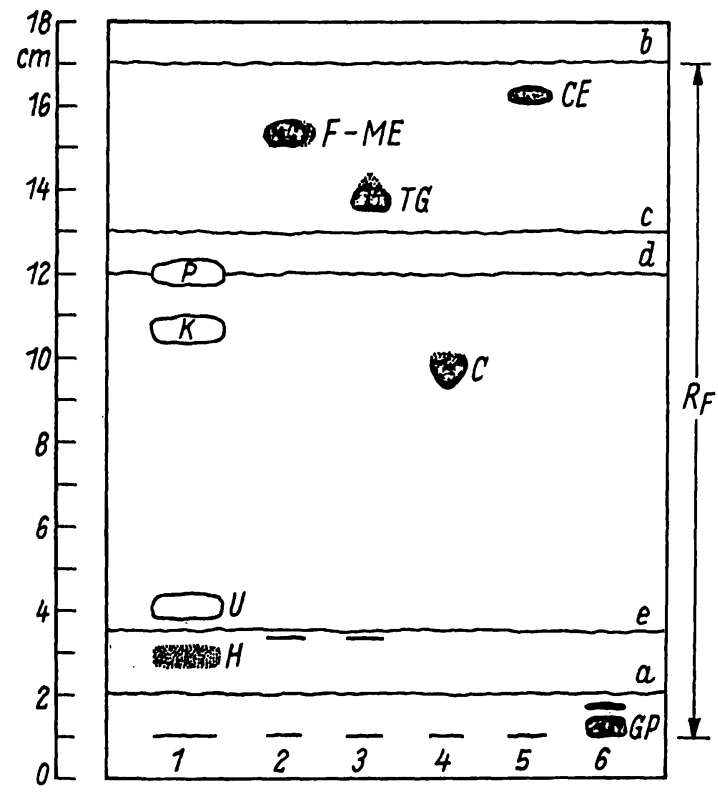

Abb. 1

Chromatographie der Porphyrinmethylester auf Kieselgel-Fertigplatten $F_{28}$ von $0,25 \mathrm{~mm}$ Schichtdicke. Lösungsmittelsysteme: a) Chloroform - Methanol $(130: 20, \mathrm{v} / \mathrm{v})$, b) Petroläther - Diäthyläther $(4: 1, v / v), c)$ Benzol - Essigsäureäthylester - Methanol $(85: 13.5: 1,5, v / v)$, d) Benzol E Essigsäureäthylester - Butanol Methanol (85:14:3:1, v/v), e) Chloroform - Methanol (100:5, v/v). Lipoide, die im Porphyrinmethylester-Chloroformextrakt aus biologischem Material vorhanden sein können, werden abgetrennt. 1 Protohämin- $(\mathrm{H})$, Uroporphyrin- $(\mathrm{U})$, Koproporphyrin- $(\mathrm{K})$ und Protoporphyrinmethylester (P), 2 Fettsäuremethylester, 3 Triglyceride, 4 Cholesterin, 5 Cholesterinester, 6 Glycerophosphatide. Uniter der Lösungsmittelfront e bei 2 und 3 freie Fettsäuren. Nachweis der Porphyrine durch Fluoreszenz (Anregung init langwelligem UV-Licht), des Hämins durch dunkelbraune Eigenfarbe und der Lipoide durch Einsprühen der Zonen mit 30 proz. Scliwefelsăure und Erhitzen auf 
b) Pctroläther (Siedebcreich $\left.40-60^{\circ}\right)-$ Diäthyläther $(4: 1, v / v)$, $16 \mathrm{~cm}$.

c) Benzol-Essigsäureäthylester-Methanol (85:13,5:1,5, v/v), $12 \mathrm{~cm}$, Lufttrocknung.

d) Benzol-Essigsäureäthylester-Butanol-Methanol (82:14:3:1, $\mathrm{v} / \mathrm{v}), 11 \mathrm{~cm}$.

e) Chloroform-Methanol (100:5, v/v), zweimal $2-3 \mathrm{~cm}$.

Im Lösungssystem b) laufen Lipoide (Cholesterinester, Triglyceride, Fettsäuremethylester) nahe der Front. Die Fettsäuremethylester entstanden unter diesen Bedingungen durch säurekatalysierte Umesterung von Glycerophosphatiden $(31,32)$ und Triglyceriden. Mit dem Lösungsmittelsystem c) werden die Porphyrin$\mathrm{ME}$ vollständig getrennt, jedoch interferiert hier noch Koproporphyrin-ME mit Cholesterin. Diese beiden Substanzen werden durch anschließende Entwicklung im Lösungsmittelsystem d) getrennt (Abb. 1). Mit dem Lösungsmittelsystem e) wird der Hämin-ME herausfraktioniert.

Porphyrin- und Hämin-ME wurden im Vergleich zu den mitgelaufenen Testsubstanzen markiert. Die Porphyrin-ME konnten durch ihre charakteristische Rotfluoreszenz unter dem UV-Licht (355 oder $366 \mathrm{~nm}$ ) und Protohämin-ME als dunkelbrauner Fleck bzw. Streifen erkannt werden. Die Nachweisempfindlichkeit der Porphyrine im langwelligen UV-Licht ist weitgehend von der Qualität der UV-Lampe abhängig. Hochdruckbrenner mit dunkelblauem Glas sind am effektivsten. Als handelsübliches Gerät verwendeten wir den DESAGA-Intensiv-Strahler. Hiermit können auf dem lösungsmittelfeuchten Chromatogramm noch 2 ng Porphyrinmethylester auf einer Fläche von $10 \mathrm{~mm}^{2}$ nachgewiesen werden. Aus den von der Glasplatte mit einer Skalpellklinge gelösten und mit Hilfe eines Stücks Aluminiumfolie in ein Faltenfilter $(\varnothing 5,5 \mathrm{~cm})$ übertragenen Kieselgelzonen eluierte man die Di- bis Pentacarboxyporphyrin-ME mit Chloroform $\left(35^{\circ}\right)$, Hexabis Oktacarboxyporphyrin-ME mit Chloroform-Methanol (9:1, $\mathrm{v} / \mathrm{v}$ ) und Protohämin mit auf $50^{\circ}$ erhitztem Chloroform-Methanol $(4: 1, \nabla / v)$. Die Lösungsmittel wurden durch Vakuumdestillation entfernt.

Spektrophotometrische Analysen

Die Porphyrin-ME wurden nach 1. c. (23) als Cu-Chelate spektrophotometrisch gemessen. Protohämin-di-ME wurde als Pyridinhämochromogen im Differenzspektrum reduziert minus oxydiert (33) bestimmt (26). Hierzu wurde der Hämin-ME in $0,4 \mathrm{ml}$ Pyridin gelöst und mit $1,6 \mathrm{~m} / 0,1 \mathrm{~N} \mathrm{NaOH}$ versetzt. Das Reaktionsgemisch wurde kurz geschüttelt und das Volumen auf zwei Halbmikroküvetten $(\mathrm{d}=2 \mathrm{~cm}$ ) verteilt. Der einen Küvette („Referenz") wurden $20 \mu / 3 \mathrm{mM} \mathrm{K} \mathrm{K}_{3} \mathrm{Fe}(\mathrm{CN})_{6}$ zur Oxydation, der anderen $\mathrm{Kü-}$ vette ("Probe“) 1 bis $2 \mathrm{mg} \mathrm{Na}_{2} \mathrm{~S}_{2} \mathrm{O}_{4}$ zur Reduktion zugesetzt. Sofort anschließend wurde das Spektrum zwischen 600 und $500 \mathrm{~nm}$ bei zwei- bis fünffacher Spreizung der Transmissionsskala registriert und die Differenz der Extinktion zwischen dem Maximum der $\alpha$-Bande bei $557 \mathrm{~nm}$ und dem Minimum zwischen den $\alpha$ - und $\beta$-Banden bei $541 \mathrm{~nm}$ bestimmt.

Die Konzentrationen der Porphyrine und des Protohämins wurden an Hand millimolarer Extinktionskoeffizienten der Cu-Chelate (23) und des Pyridinhämochroms (34) berechnet. Für Protoporphyrinmethylester galt $\varepsilon_{\mathrm{mM}}^{404}=277$, für das Pyridinhämochrom aus Protohäminmethylester $\varepsilon_{\mathrm{m} 3 \mathrm{I}}=21,2$ (26).

\section{Ergebnisse}

\section{Hühnerembryo-Leberzellkulturen}

Die zum Ansetzen der Zellkulturen verwendete Leberzellsuspension war nicht völlig frei von Erythrocyten und Zelltrümmern. Die Erythrocyten gingen aber, ebenso wie Leberzellfragmente, nicht in den Zellkulturrasen ein. Beim Wechsel des Wuchsmediums nach 24 Stdn. wurden dann Erythrocyten, Zellfragmente und einzelne, nicht angewachsene Zellen entfernt. Eine Ver- mehrung der Leberzellen in der Kultur wurde nach mikroskopischen Kontrollen nicht beobachtet. Sie ist, wie bereits GRANICK (1) berichtet hat, für die Induktion auch nicht erforderlich. Mikroskopische Unterschiede an den Leberzellen zwischen induzierten und nichtinduzierten Kulturen konnten im Laufe der zweitägigen Inkubation nicht festgestellt werden. Relativ große Mengen der induzierenden. Substanzen führten zu Zellsschäden: Risse in der Zellwand, Destruktion des Zellkerns. (Zellschäden dieser Art können auch nach zu schneller Zentrifugation und/oder hoher Temperatur des Brutschrankes auftreten, wie elektronenmikrokopische Kontrollen zeigten $\left.{ }^{3}\right)$.)

Die Reaktionsfähigkeit der in Kultur gehaltenen Zellen zur Induktion ist nach $24 \mathrm{Stdn}$. am stärksten. Sie ist am dritten Tag, wenn auch schwächer, noch vorhanden. Danach geht die Eigenschaft der Zellen zur Induktion verloren. Andererseits kann auch in der frisch angesetzten Kultur eine Induktion ausgelöst werden, wofür man die Substanz entweder sofort bei Anlegen der Kulturen oder zu dem Zeitpunkt zusetzt, wenn der größte Teil der Zellen bereits am Glasboden der Zellkulturschale haftet, was in der Regel zwischen zwei und fünf Stdn. eingetreten ist. Zwar ist die Auswirkung der beiden Applikationszeiten vor dem Mediumwechsel auf die Porphyrinsynthese gering, doch sind die bereits am Glas angewachsenen Leberzellen besser zu indúzieren, so da $\beta$ in diesem Falle höhere Porphyrinkonzentrationen entstehen. Bei der Induktion nach dem Mediumwechsel (s. Methodik) wurde mit 2-Methyl-2-n-propyl-1,3propandioldicarbamat $(200 \mu \mathrm{g} / \mathrm{m} l$ Medium) eine maximal doppelt so hohe Porphyrinsynthese erzielt als bei der Applikation des Induktors drei Stdn. nach Ansetzen der Kulturen. Mit Steroiden wurde dagegen innerhalb desselben Versuchsansatzes keine wesentlich höhere Porphyrinsynthese bei der Induktion vor und nach dem Mediumwechsel gefunden. Während die Reaktionsfähigkeit der Zelle zur Induktion nach einer Inkubationszeit von drei Tagen verlorengeht, bleibt ihre Fähigkeit, Porphyrine aus der $\delta$-Aminolävulinsäure zu bilden, länger erhalten. Vier und auch fünf Tage alte Leberzellkulturen synthetisieren noch Uro- und kleine Mengen von Koproporphyrin aus zugesetzter $\delta$-Aminolävulinsäure. Allerdings sind die Syntheseraten aus $\delta$-Aminolävulinsäure gegenüber den sofort oder nach den ersten 24 Stdn. induzierten Zellen viel geringer.

Die absoluten Mengen der nach Induktion durch dieselbe in der gleichen Konzentration hinzugefügte Substanz synthetisierten Porphyrine unterlag einer Variationsbreite von etwa $\pm 30 \%$ in voneinander unabhängig durchgeführten Experimenten. Dieser Bereich wurde mit Meprobamat $(200 \mu \mathrm{g} / \mathrm{m} / \mathrm{Medium})$ ermittelt. Die Variabilität (1) der Analysendaten zwișchen den einzelnen Versuchsreihen beruht auf biologischen Variationen in den Lebern der Hühnerembryonen,

3) Freundlicherweise von Herrn Professor Dr. W. VoGell, Institut für Physikalische Biologie und Elektronenmikroskopie der Universität Marburg/Lahn durchgeführt. 
Untcrschieden des jeweils verwendeten Kälberserums, verschieden langer Dauer der Trypsinierung und physikalischen Differenzen der Inkubationsbedingungen. Deshalb sind die absoluten Analysendaten nur innerhalb einer Versuchsreihe vergleichbar. Die in den Abbildungen 2, 3, 4 und 6 dargestcllten Resultate wurden aus Versuchen erhalten, deren Bedingungen identisch waren.

Verteilung der Porphyrine zwischen Zellen und Medium

In den nicht-induzierten Kulturen war die Konzentration der Porphyrine bei den meisten Experimenten so niedrig, daß zu ihrer Bestimmung mehrere Extrakte gepoolt werden mußten. Dabei ergab sich aus chromatographischen Analysen, daß Protoporphyrin zum überwiegenden Teil in den Zellen und nur in Spuren im Überstand, dagegen Koproporphyrin zu etwa gleichen Teilen in Zellen und Überstand vorkommen. In den mit Meprobamat $(200 \mu \mathrm{g} \mathrm{m} /)$ induzierten Leberzellkulturen befanden sich Koproporphyrin zu $62 \%$, Protoporphyrin zu $41 \%$ und Porphyrine mit 5 bis 8 Carboxylgruppen fast ausschließlich im Medium. $\delta$ Aminolävulinsäure und Porphobilinogen, die mit einer modifizierten (35) Methode nach Mauzerall und Granick (36) bestimmt wurden, fanden sich zu $72 \%$ und $61 \%$ in den Zellen. Ein solcher Verteilungstyp der Produkte der Hämsynthese wurde auch unter dem Einfluß anderer streng induzierender Pharmaka wie Glutethimid und Methyprylon sowie nach Induktion mit Ätiocholanolon gefunden. Die Gesamtsynthese des Protoporphyrins wurde in den Experimenten (s. Abb. 2 bis 6) in Zellen und Medium zusammen analysiert (s. Methodik).

Porphyrinsynthese im zeitlichen Verlauf der Inkubation

Der zeitliche Verlauf der Gesamtsynthese stimmt mit den Ergebnissen von Granick und Kappas $(1,11)$ überein, die in ihren Induktionsversuchen die $\mathrm{Zu}$ nahme der Porphyrinsynthese fluoreszenzmikroskopisch verfolgt haben. Der Syntheseanstieg begann in den meisten Experimenten zwischen sechs und neun Stdn. Entgegen der Erwartung, daß gemäß der Synthesekette der Porphyrine zuerst Uro-, dann Kopround zuletzt Protoporphyrin gebildet werden, zeigten sämtliche Induktionsversuche an Leberzellkulturen, daß zuerst die Synthese von Protoporphyrin ansteigt (37), dessen Konzentration nach $20 \mathrm{Stdn}$. für die Intensität ciner induzierten Substanz auf die Porphyrinsynthese in den Hühnerembryo-I_eberzellen charakteristisch ist. Dem Anstieg des Protoporphyrins folgten das Tricarboxyporphyrin, dann Koproporphyrin und bei Anwesenheit eines sehr starken Induktors nach 14 bis 16 Stdn. auch Uroporphyrin (37).

Induktion der Porphyrinsynthese durch Pharmaka

Die folgenden chemischen Fremdstoffe, vorwiegend Pharmaka, wurden Leberzellkulturen zugesetzt:
1. 2-Methyl-2-n-propyl-1,3-propandioldicarbamat (Meprobamat, $200 \mu \mathrm{g} / \mathrm{m} /$ ).

2. 1,4-Dihydro-2,4,6-trimethyl-3,5-dicarbäthoxy-pyridin (Diäthyl-1,4-dihydro-2,4,6-trimethylpyridin-3,5-dicarboxylat, 3,5-Dicarbäthoxy-1,4-dihydrocollidin, DDC10 $\mu \mathrm{g} /$ $\mathrm{m} /)$.

3. 2,4-Dioxo-3,3-diäthyl-5-methylpiperidin (Methyprylon, $100 \mu \mathrm{g} / \mathrm{m} /$ ).

4. $\alpha$-Phenyl- $\alpha$-äthylglutarsäureimid (Glutethimid, $40 \mu \mathrm{g} /$ $\mathrm{m} /)$.

5. Diallylbarbitursäure $(120 \mu \mathrm{g} / \mathrm{m} /)$.

6. 1-Phenyl-2-( $p$-hydroxyphenyl)-3,5-dioxo-4-n-butylpyrazolidin-monohydrat ( $p$-Hydroxy-phenylbutazon, $200 \mu \mathrm{g} / \mathrm{m} /$.

7. 7-Chlor-4-(4'-diäthylamino-1'-methylbutylamino)-chinolindiphosphat (Chloroquindiphosphat, $150 \mu \mathrm{g} / \mathrm{m} /$ ).

8. 2-(Sulfanilamido)-4,5-dimethyloxazol $(200 \mu \mathrm{g} / \mathrm{m} /)$.

9. Chloramphenicol $(150 \mu \mathrm{g} / \mathrm{m} /)$.

10. Griseofulvin $(25 \mu \mathrm{g} / \mathrm{m} /)$.

11. Tylosin $(200 \mu \mathrm{g} / \mathrm{m} /)$.

Die Substanzen wurden in der angegebenen Konzentration den Kulturen nach dem Mediumwcchsel (24 Stdn.) zugesetzt. Die verschiedenen Konzentrationen der Substanzen sind in Vorversuchen für die Induktion der Porphyrinsynthese an den Leberzellkulturen als besonders wirksam ermittelt worden. Chloroquindiphosphat, Chloramphenicol, Griseofulvin und Tylosin führten nur zu einem Anstieg des Protoporphyrins. Dagegen kam es unter Einwirkung stark induzierender Substanzen wie Meprobamat, DDC, Methyprylon, Glutethimid, aber auch bei $p$-Hydroxy-phenylbutazon,

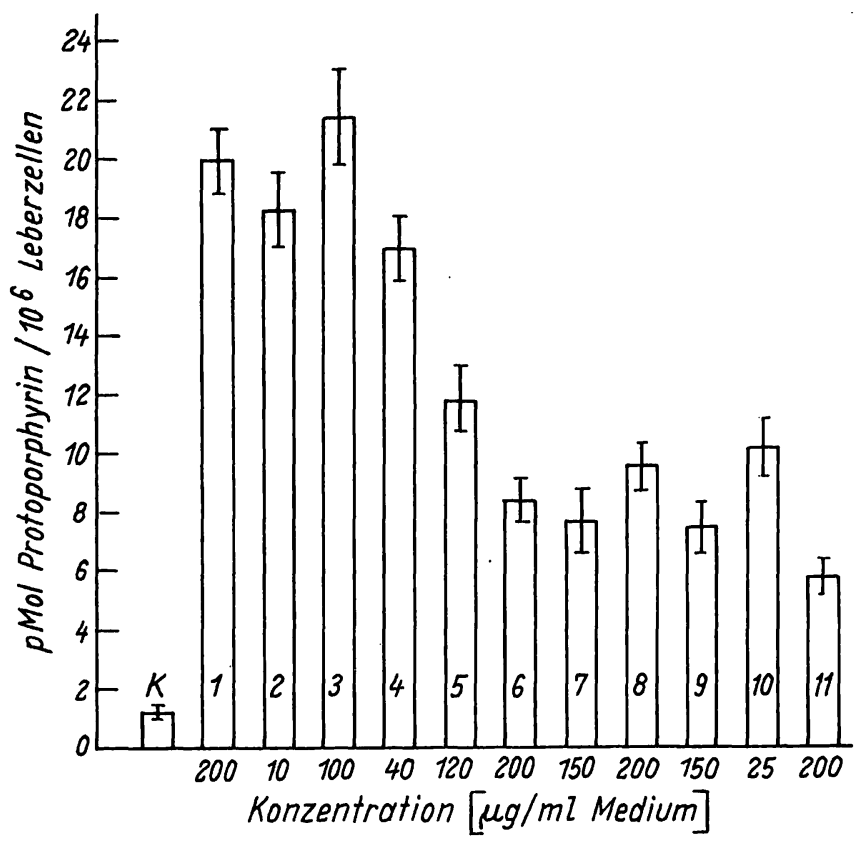

Abb. 2

Wirkung chemischer Fremdstoffe auf die Synthese von Protoporphyrin in Hühnerembryo-Leberzellkulturen. Zusatz der Substanzen in den angegebenen Mengen ( $/ \mathrm{g} / \mathrm{ml}$ Medium) zu 24 Stdn. inkubierten Kulturen nach dem Wechsel des Wuclismediums. Analysen nach einer weiteren Inkubationszeit von 24 Stdn. Die Standardabweicliung voin arithmetischen Mittel $(n=4)$ ist eingezeichnet. 1 Meprobamat, 2 3,5-Dicarbäthoxy-1,4-dihydrocollidin, 3 Methyprylon, 4 Glutethimid, 5 Diallylbarbitursäure, 6 p-Hydroxy-phenylbutazon, 7 Chloroquindiphosphat, 8 2-(Sulfanilamido)-4,5-dimethyloxazol, 9 Chloram-
phenicol, 10 Griseofulvin, 11 Tylosin 
ebenfalls zu einer Erhöhung des Kopro- und Uroporphyrins, deren Konzentration jedoch niemals signifikant über der Konzentration des Protoporphyrins nach 22stdg. Inkubation lag (37). Deshalb ist der Syntheseanstieg des Protoporphyrins für die Intensität der Induktion und damit für die Wirkung des Pharmakons auf die Porphyrinsynthese charakteristisch. Die Resultate sind in Abbildung 2 dargestellt. Das PPLO-Agens Tylosin führte auch bei Ratten nach peroraler Gabe zu dosisabhängigen passageren Erhöhungen der Ausscheidung von $\delta$-Aminolävulinsäure, Porphobilinogen und Koproporphyrin im Urin (71).

\section{Induktion durch Steroide}

Der Einfluß folgender Steroide auf die Porphyrinsynthese wurde in den Leberzellkulturen untersucht:

1. $5 \beta$-Androstan-3 $\alpha$-ol-17-on.

2. $5 \beta$-Androstan-3,17-dion.

3. $5 \beta$-Androstan-17 $\beta$-ol-3-on.

4. $5 \alpha$-Androstan-17 $\beta$-ol-3-on.

5. $5 \beta$-Pregnan-3 $\alpha-17 \alpha-20 \alpha$-triol.

6. $5 \beta$-Pregnan- $3 \alpha, 20 \alpha$-diol.

7. $5 \beta$-Pregnan-3,20-dion.

8. $5 \alpha$-Pregnan-3,20-dion.

9. $\Delta^{4}$-Pregnen-3,20-dion.

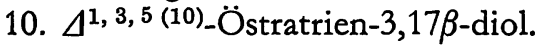

11. Cholesterinoleat.

12. Cholsäure.

Die Konzentration der Steroide betrug $5 \mu \mathrm{g} / \mathrm{m} l$ Medium. Induzierende Steroide haben einen in quantitativer Hinsicht schwächeren Effekt auf die Porphyrinsynthese gegenüber den Pharmaka Meprobamat, Methyprylon, Glutethimid sowie auch gegenüber 3,5-Dicarbäthoxy1,4-dihydrocollidin. Dementsprechend trat eine erhöhte Bildung von Kopro- und Uroporphyrin ebenfalls nicht in dem Ausmaß, wie sie Meprobamat bewirkte, unter dem induzierenden Einfluß von Steroiden ein (37). Die Wirkung der verschiedenen Steroide auf die Synthese von Protoporphyrin ist in Abbildung 3 wiedergegeben. Außer Progesteron und Östradiol stimulierten vorwiegend $5 \beta$-H-Steroide (A:B-cis) die Porphyrinsyn-

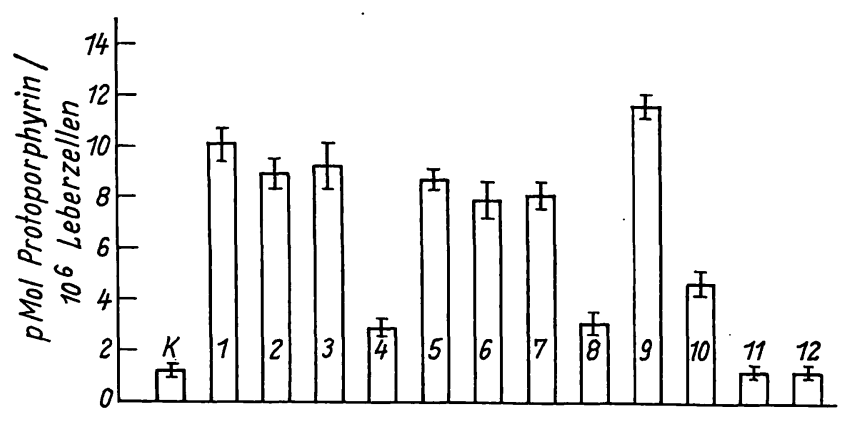

Abb. 3

Wirkung verschiedener Steroide auf die Synthese von Protoporphyrin in Hühnerembryo-Leberzellkulturen. Zusatz der Steroide während des Mediumwechsels nach 24 Stdn. Analysen $(\bar{x} \pm s \bar{x} ; n=4)$ nach weiteren 24 Stdn. Inkubation. $15 \beta$-Androstan-3x-ol-17-on, $25 \beta$ Androstan-3,17-dion, $35 \beta$-Androstan-17 $\beta$-ol-3-on, $45 \alpha$-Androstàn

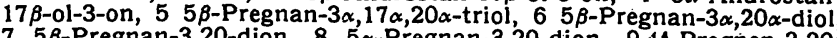
$75 \beta$-Pregnan-3,20-dion, 8 5 $\alpha$-Pregnan-3,20-dion, 9 $\Delta^{4}$-Pregnen-3,20dion, $10 \Delta^{1,3,5}\left(1^{10}\right)$-Östratrien-3,17 $\beta$-diol, 11 Cholesterinoleat, $12 \mathrm{Chol}$ säure, je $5 \mu \mathrm{g} / \mathrm{ml}$ Medium
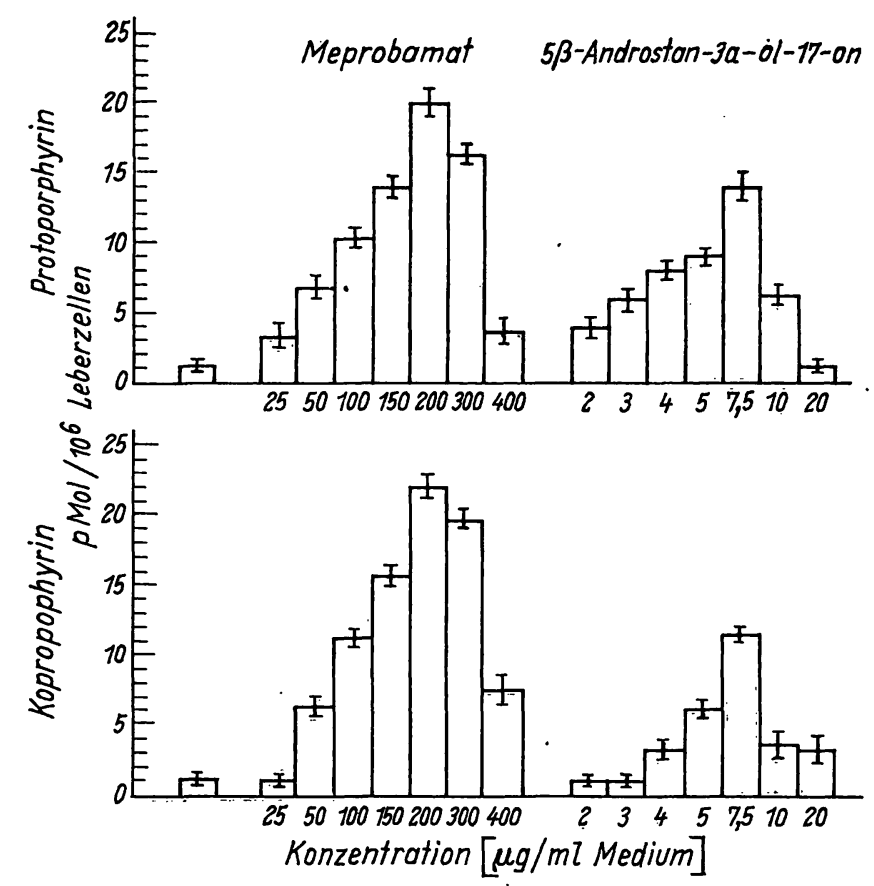

Abb. 4

Beziehung zwischen dem Syntheseanstieg des Protoporphyrins und der Konzentration der induzierenden Substanz im Medium der Leberzellkulturen

these. Die Resultate stimmen im wesentlichen mit den fluoreszenzmikroskopischen Befunden von GríANicK und Kappas $(11,12)$ überein.

Abhängigkeit der Induktion von der Konzentration der induzierenden Substanz

Meprobamat und Ätiocholanolon wurden den Zellkulturen in steigenden Mengen zugesetzt. Die Porphyrinsynthese stieg mit Zunahme der Konzentration des Induktors im Medium zunächst an und erreichte bei einer bestimmten Konzentration ein Maximum. Dieses Wirkungsmaximum lag für Meprobamat in mehreren Versuchen $z$ wischen 200 und $250 \mu \mathrm{g} / \mathrm{m} l$ Medium und für Ätiocholanolon zwischen 5 und 7,5 $\mathrm{g} / \mathrm{m} /$. Die typischen Ergebnisse eines Versuchs zeigt Abbildung 4. Es handelt sich um Analysendaten von 24 Stḍn. inkubierten Kulturen. Das Carbamat wirkte stärker als Ätiocholanolon. Die Proto- und Koproporphyrinsynthese verliefen zunächst gleichsinnig in Abhängigkeit von der zugesetzten Menge des Induktors bis zu dessen Wirkungsmaximum. Hohe Konzentrationen der zugesetzten Substanzen führten hingegen zu morphologischen Veränderungen der Zelle (s. unter Zellkulturen S. 136). Geschädigte Zellen (Meprobamat $400 \mu \mathrm{g} / \mathrm{ml}$, Ätiocholanolon $20 \mu \mathrm{g} / \mathrm{m} l$ ) synthetisierten vorwiegend Koproporphyrin.

Der Effekt des Meprobamats (200 $\mu \mathrm{g} / \mathrm{m} /$ Zellsuspension) war in jedem Leberzellkulturversuch innerhalb der Variabilität de's biologischen Systems reproduzierbar. Meprobamat wurde deshalb ais „Indikator"-Substanz verwendet, um die Eignung der unter den Bedingungen der Zellkultur inkubierten Leberzellen für die Induktion der Porphyrinsynthese zu prüfen und die Syntheseleistung der einzelnen Versuche miteinander quantitativ zu vergleichen. Als eine Testsubstanz mit stark induzierenden Eigenscháften bot sich auch DOC an. Jedoch hat DDC für die hier 
verwendetc Aufarbeitungstechnik einige Nachteile, dic darin bestehen, daß cs nach der Veresterung cbenfalls durch Chloroform mitextrahicrt und sich dünnschichtchromatographisch in mehrerc Fraktionen auftrennt, dic im UV-Licht $(355 \mathrm{~nm})$ intensiv hellblau fluoreszieren, mit den $R_{\mathrm{F}}$-Zonen der Porphyrinmethylester, insbesondere des Kopro- und Protoporphyrins, interferieren und dadurch deren Nachweisempfindlichkeit einschränken. (Eine Abtrennung des DDC gelang durch Mehrfach-Chromatographie im Lösungsmittclsystem Benzol-Äthylacetat $(9: 1, v / v)$, wenn das Chromatogramm nicht vorher schon in anderen Lösungsmittelsystemen entwickelt worden war.)

Einfluß einiger Pharmaka und Stcroide auf die Porphyrinsynthese aus $\delta$-Aminolävulinsäure

Aus $\delta$-Aminolävulinsäure, die in einer Konzentration von $0,1 \mathrm{~mm}$ mit dem Wechsel des Wuchsmediums hinzugegeben wurde, synthetisieren Hühnerembryo-Leberzellen erheblich größere Mengen an Porphyrinen als nach Induktion durch Meprobamat oder DDC. Gegenüber den Zellkulturen (Kontrollen) ohne Zusatz von $\delta$-Aminolävulinsäure wurden nach einer Inkubation von $24 \mathrm{Stdn}$. $100 \mathrm{fach}$ mehr Protoporphyrin, 30 - bis 40 fach mehr Koproporphyrin und etwa 20- bis 30 fach mehr Uroporphyrin gefunden. In den Inkubationsperioden vor und nach dem Mediumwechsel wurden nicht nur unterschiedliche Mengen von $\delta$-Aminolävulinsäure für die Porphyrinsynthese utilisiert, sondern auch die Synthese der einzelnen Porphyrine selbst war verschieden groß. So ergab sich im Vergleich der Porphyrinkonzentrationen der Gesamtkultur nach 24 und $48 \mathrm{Stdn}$., also nach Zusatz von $\delta$-Aminolävulinsäure bei der Inkubationszeit 0 und $24 \mathrm{Stdn}$., daß in der zweiten Inkubationsperiode die Synthese von Proto- und Uroporphyrin abnahm, obwohl diejenige von Koproporphyrin anstieg. Der Befund ist im Zusammenhang mit der Beobachtung zu erklären, daß drei Tage in Kultur inkubierte Leberzellen die Porphyrinsynthese nicht mehr bis zum Protoporphyrin durchführen können. Neben der Induzierbarkeit der $\delta$-Aminolävulinsäuresynthetase nimmt auch die Aktivität der Koproporphyrin-Oxydase im Verlaufe der Kultivierung schneller ab als die Aktivitäten der $\delta$-Aminolävulinsäure-Dehydratase und des vom Uro- zum Koproporphyrinogen führenden Decarboxylierungs-Systems ${ }^{2}$ ). Die relativ geringe Uroporphyrinkonzentration bei der Synthese aus $\delta$-Aminolävulinsäure am Ende der zweiten Inkubationsperiode resultiert, wie Verlaufsstudien der Synthesesequenzen zeigten, daraus, daß Uroporphyrinogen überwiegend zu Koproporphyrin metabolisiert wurde. Es ist anzunehmen, daß die mit dem Rückgang der Protoporphyrinsynthese synchron und auch quantitativ korrelierende Erhöhung der Koproporphyrinsynthese durch Regulationsmechanismen auf dem Niveau einer feedback-Kontrolle gesteuert wird. Wahrscheinlich versucht die Zelle, eine verminderte Fähigkeit zur Protoporphyrinsynthese durch einen verstärkten „Nachschub“ von höher carboxylierten Porphyrinogenen auszugleichen. Die Hypothese, daß in der Leberzelle zwischen den Synthesesequenzen, die von der $\delta$-Aminolävulinsäure zum Protohäm führen, Kontrollmechanismen

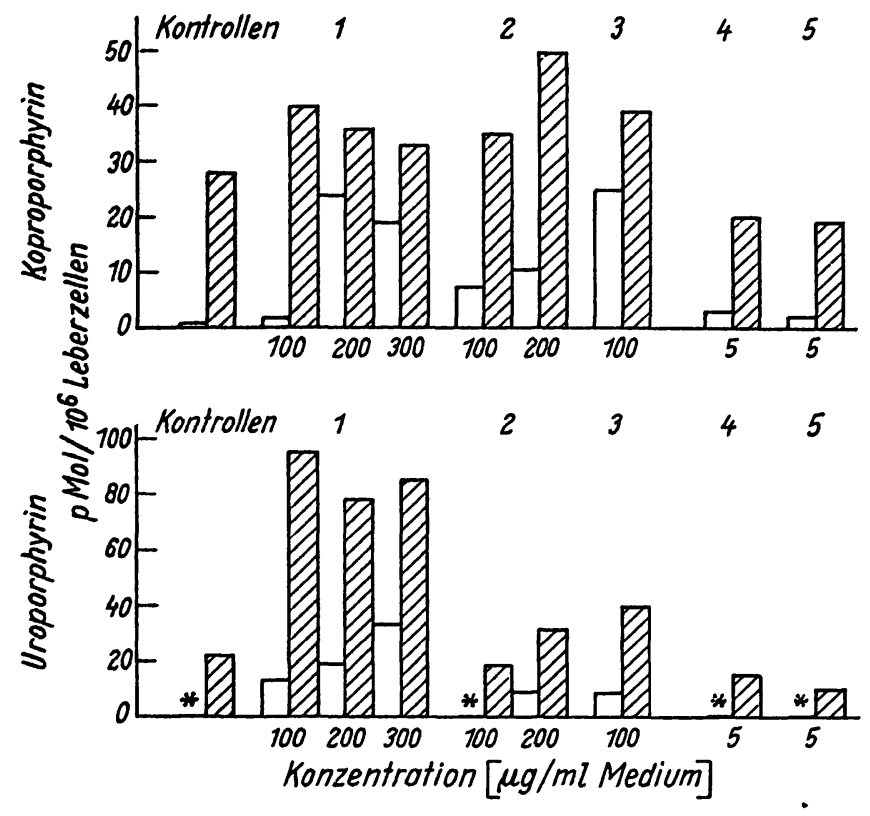

Abb. 5

Einfluß einiger Pharmaka und Steroide auf die Synthese von Kopround Uroporphyrin mit (schraffiert) und ohne (offene Säulen) Zusatz von o-Aminolävulinsäure (ALS) zum Wuchsmedium. Konzentration von o-Aminolavulinsaure (ALS) zum Wuchsmedium. Konzentration Methyprylon, 4 Progesteron, 5 Ostradiol

Zeichenerklärung: * auf dem Chromatogramm kein Fluoreszenznachweis

existieren, wird weiterhin durch die Experimente gestützt, in denen sich zeigte, daß nach der Zugabe von Meprobamat $(100-300 \mu \mathrm{g} / \mathrm{m} /)$ zur Zellkultur die Konzentration von Uroporphyrin und nach der Zugabe von $p$-Hydroxy-phenylbutazon $(200 \mu \mathrm{g} / \mathrm{m} /)$ die Konzentration von Koproporphyrin anstieg (Abb. 5). Das relative Ausmaß des Anstiegs der Porphyrine aus zugesetzter $\delta$-Aminolävulinsäure $(0,1 \mathrm{~mm})$ unter dem Einflu $\beta$ von Pharmaka ist allerdings viel geringer als bei den Induktionsversuchen. Inhibitoren der Nucleinsäure- und Proteinsynthese (s. S. 140) hatten sowohl in den Kontrollen als auch in den mit Pharmaka beschickten Kulturen nur geringen Einfluß auf die Synthese aus $\delta$-Aminolävulinsäure, so da $\beta$ ein Induktionsprozeß demzufolge für den in Abbildung 5 dargestellten Pharmakaeffekt nicht verantwortlich sein wird. Außerdem ist $\delta$-Aminolävulinsäure selbst ein potenter Repressor auf die $\delta$-Aminolävulinsäure-Synthetase (15). Der größte Teil der unter Zusatz von $\delta$-Aminolävulinsäure in der Hühnerembryo-Leberzelle gebildeten Porphyrine wird an das Medium abgegeben. In dieser Hinsicht verhält sich die Leberzelle ähnlich wie eine Baktcrienzelle. Auch ein zur Hämsynthese fähiger Mikroorganismus gibt die aus zum Medium zugesetzter $\delta$ Aminolävulinsäure synthetisierten Porphyrine, die aus diesem Vorläufer in verhältnismäßig großer Konzentration gebildet werden können, vorwiegend an das Medium ab (8). Wenn morphologisch und funktionell so extrem verschiedene Zellen in bezug auf die Abgabe von Porphyrinen aus der Zelle ein im Prinzip gleichartiges Verhalten zeigen, liegt es nahe, daß sich hinter dieser Beobachtung eine allgemeine biologische Regel verbirgt. 
Identifizierung von Protoporphyrin

Die Porphyrine wurden auf dem Dünnschichtchromatogramm gegenüber authentischen Vergleichssubstanzen lokalisiert. Zur Identifizierung mußten jedoch ausreichende Mengen an Reinsubstanzen zur Verfügung stehen, die durch Rechromatographie in denselben Lösungsmittelsystemen isoliert werden konnten. Die Substanzen wurden aus den Leberzellkulturen gewonnen, die Porphyrine aus zugesetzter $\delta$-Aminolävulinsäure synthetisierten. Sowohl die $R_{\mathrm{F}}$-Werte der einzelnen Porphyrine als auch die Absorptionsmaxima der Porphyrinmethylester in Chloroform und der Kupfer-Chelat-Komplexe stimmten mit den Daten der Vergleichssubstanzen überein. Die nach dem chromatographischen Verhalten in verschiedenen Lösungsmittelsystemen und den Absorptionsmaxima in Chloroform, $\ddot{A}$ ther und Dioxan als Protoporphyrin-IX-dimethylester bezeichnete Substanz wurde mit der Eisensulfat-Methode (34) in Protohämin und mit einer BromwasserstoffEisessig-Lösung in Hämatoporphyrin umgewandelt (38). Protohäminmethylester wurde chromatographisch gereinigt (22) und an Hand seines Differenzspektrums nachgewiesen (26). Die aus Protoporphyrin erhaltene Hämatoporphyrinfraktion wurde rückverestert, und Hämatoporphyrin-IX-methylester wurde chromatographisch und spektrophotometrisch analysiert und wie früher beschrieben identifiziert (38).

Porphyrine mit 3, 5, 6 und 7 Carboxylgruppen

Unter der Einwirkung von Meprobamat (200-300 $\mu \mathrm{g} / \mathrm{m} l)$, DDC $(10 \mu \mathrm{g} / \mathrm{m} /)$ und Glutethimid $(40 \mu \mathrm{g} / \mathrm{m} l)$ stieg nicht nur die Synthese der 2-, 4- und 8-Carboxyporphyrine an, sondern auch eine Fraktion, die chromatographisch zwischen Proto- und Koproporphyrin wanderte und am ehesten ein Triacarboxyporphyrin darstellt. Außerdem befanden sich in diesen Zellkulturen Porphyrine mit 5, 6 und 7 Carboxylgruppen, die mittels Vergleichssubstanzen, die aus einer früheren Arbeit vorhanden waren (22), nachgewiesen werden konnten.

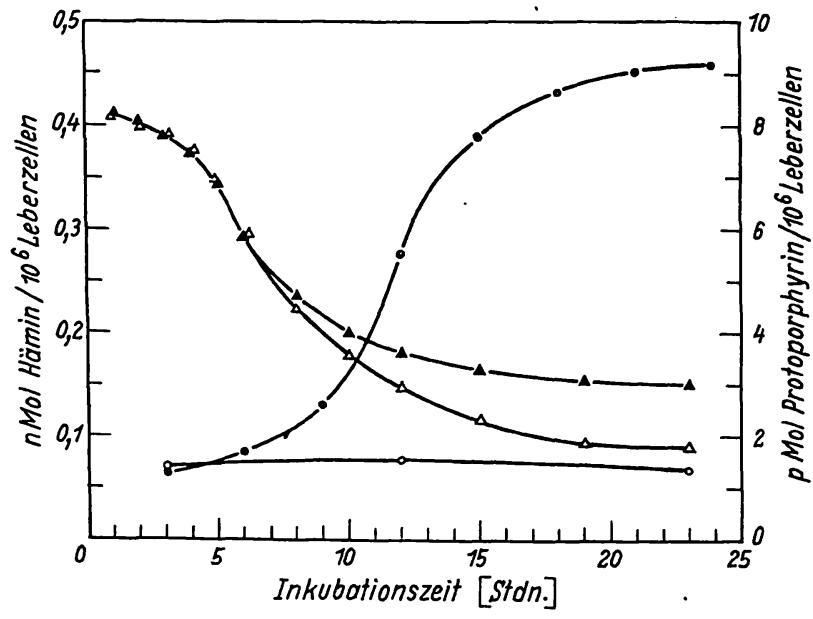

Abb. 6

Protohämgehalt der mit Meprobamat $(150 \mu \mathrm{g} / \mathrm{ml}$ Medium) induzierten Hühnerembryo-Leberzellkulturen im Vergleich zur Konzentration des gebildeten Porphyrins

$\begin{array}{ccc}\text { Hämin } & & \text { Potoporphyrin } \\ \triangle & \text { Kontrolle } & \text { Peprobamat }\end{array}$

\section{Protohämgehalt der Leberzellkulturen}

Bei der Veresterung der Porphyrine und Extraktion der Porphyrinmethylester erhielt man gleichzeitig den Protohäminmethylester, der ebenfalls vom Adsorbens eluiert und dann differenzspektrophotometrisch als Pyridinhämochrom analysiert wurde.

Aus Abbildung 6 geht hervor, daß die Protohämkonzentration in sämtlichen Kulturen vorwiegend während der ersten 10 Stdn. abfällt. Nach 10 Stdn., zu dem Zeitpunkt also, an dem die Protoporphyrinsynthese maximal ansteigt, fällt in den mit Meprobamat (Abb. 6), DDC, Glutethimid, Methyprylon und Diallylbarbitursäure induzierten Kulturen die Konzentration des Hämins gegenüber der Kontrolle geringer ab, so daß gegen Ende der Inkubationszeit ein höherer Protohämingehalt in der induzierten Kultur resultierte (26). Es ist noch zu beweisen, ob der Rückgang des Hämingehaltes im Verlaufe der Inkubation lediglich durch den Abfall der Katalase entsteht und ob der erhöhte Gehalt an Protohämin in der induzierten Kultur am Ende der Inkubation auf eine echte Neusynthese von Protohäm zu beziehen ist. Für eine Neusynthese spricht die Tatsache, $\mathrm{da} \beta$ in Kulturen mit 0,1 mM $\delta$-Aminolävulinsäure in den letzten $10 \mathrm{Stdn}$. der Inkubationsperiode mehr Protcporphyrin gefunden wurde. Die Unterschiede im Hämgehalt zwischen diesen und mit Meprobamat induzierten Kulturen, die ebenfalls $\delta$-Aminolävulinsäure enthielten, waren aber nicht signifikant. Den Kulturen zugesetztes freies Protoporphyrin (1 bis $5 \mu \mathrm{M}$ ) wurde partiell in Häm überführt.

Einfluß von Protohämin und Inhibitoren der Nucleinsäure- und Proteinsynthese

Setzt man den Kulturen gleichzeitig mit dem Pharmakon auch Hämin in Konzentrationen zwischen 10 und $100 \mu \mathrm{Mr}$ zu, wird die Wirkung des Pharmakons weitgehend aufgehoben. In einer Konzentration von $50 \mu \mathrm{M}$ hemmt Protohämin, das in einer nach den Angaben von LASCELIES hergestellten Lösung (15) zugesetzt wurde, die durch Meprobamat induzierte Porphyrinsynthese um etwa $80 \%$. Um eine direkte Reaktion zwischen Pharmakon und Hämin auszuschließen, wurden differenzspektrophotometrische Analysen von Protohämin-Meprobamat-Gemischen in wäßrigen und organischen Lösungsmitteln durchgeführt. Es fanden sich jedoch keine Hinweise, die auf eine Komplexbildung zwischen diesen beiden Substanzen schließen lassen. Inhibitoren der Nucleinsäuresynthese (39), wie Actinomycin D und Mitomycin C, verhindern den induzierenden Effekt von Pharmaka und Steroiden auf die Porphyrinsynthese. Die Wirkung der Inhibitoren ist dosisabhängig (12). Actinomycin $\mathrm{D} 0,1 \mu \mathrm{g} / \mathrm{ml}$ oder Mitomycin C $10 \mu \mathrm{g} / \mathrm{m} l$, die gleichzeitig mit Meprobamat, DDC, Glutethimid, Methyprylon oder Ätiocholanolon; $5 \beta$-Androstan-17 $\beta$-ol-3-ón und 5 $\beta$-Pregnan-3 $\alpha, 17 \alpha, 20 \alpha-$ triol appliziert wurden, inhibierten den Anstieg der Porphyrinsynthese vollständig. Ebenfalls wurde in Zellkulturen, denen mit Meprobamat oder $p$-Hydroxyphenylbutazon $(200 \mathrm{mg} / \mathrm{m} /)$ gleichzeitig Puromycin (39) 
in einer Konzentration von $12 \mu \mathrm{g} / \mathrm{m} /$ hinzugefügt wurde, nach 22 Stdn. kein von der Kontrollkultur abweichender Prophyringehalt gefunden.

In vivo Experimente an Hühnerembryonen 16 Tage alten Hühnerembryonen wurden $5 \mathrm{mg}$ Meprobamat in den Luftsack injiziert. Die Kontrollen erhielten das entsprechende Volumen des Lösungsmittels $(20 \mu l$ 0,85proz. $\mathrm{NaCl} /$ Äthanol 2:1, v/v). Nach $20 \mathrm{Stdn}$. wurden die Lebern von je drei Embryonen präpariert, zerschnitten, tiefgefroren, lyophilisiert und in Portionen von 10 bis $12 \mathrm{mg}$ ausgewogen. Das Trockengewicht der Lebern lag bei $45 \mathrm{mg}$ in den Kontrollen und bei den induzierten Embryonen um 16\% höher. Auf dem Dünnschichtchromatogramm der aus Leberproben der Kontrollen aufgetrennten Extrakten war keine Porphyrinfluoreszenz feststellbar. Dagegen ließ sich im Chromatogramm der Leberextrakte von Embryonen, die Meprobamat erhalten hatten, Protoporphyrin und Koproporphyrin fluoreszenzoptisch nachweisen. Die Konzentration beider Porphyrine lag bei $5 \mathrm{pMol} / \mathrm{mg}$ Trockengewicht.

\section{Diskussion}

Sowohl von klinischer wie von biochemischer Seite liegt eine große Anzahl von Befunden vor, die zur Aufklärung des Wirkungsmechanismus von Pharmaka und organisch-chemischen Fremdstoffen auf die Porphyrinsynthese beim Menschen und am Versuchstier beigetragen haben. Zusammenfassende Darstellungen geben Brugsch (40), Stich (41, 42), Goldberg und Rimington (43) und das Ciba Foundation Symposium im Jahre 1955 (44).

Mit den Erkenntnissen über die Gen-abhängige Steuerung von Regulationsmechanismen (2) biologischer Synthesen haben sich neue Vorstellungen nicht nur über die Wirkung von Pharmaka auf die Porphyrin- und Hämsynthese, sondern auch zur Pathogenese der hepatischen Porphyrien des Menschen herausgebildet (45). Hinzu kommen von pharmakologischer Seite Untersuchungen über die Induktion arzneimittelabbauender Enzyme (46, 47, 48) und über die Stimulation des Leberwachstums unter Fremdstoffeinwirkung $(49,50,51)$, insbesondere bei experimenteller Porphyrie $(52,53,54,55)$, sowie elektronenmikroskopische Beobachtungen über Veränderungen an den Mitochondrien (56) und am endoplasmatischen Retikulum $(57,58,59)$ unter der Wirkung von Pharmaka auf die Leber des Versuchstieres.

\section{Besprechung der Experimente}

Die ersten Hinweise auf eine de novo Synthese des ersten Enzyms der Hämsynthese in der Leber durch chemische Fremdstoffe, der eine Erhöhung der Porphyrinsynthese folgt, gaben GrANICK und URATA (56). Sie verfütterten an Meerschweinchen DDC, über dessen porphyrogene Wirkung beim Versuchstier erstmals Solomon und FIGGe $(60,61)$ berichtet hatten, und stellten in den
Mitochondrien der Leberparenchymzellen einen 40fachen Anstieg der $\delta$-Aminolävulinsäure-Synthetase fest. Sie beobachteten bereits während der ersten Tage des Experiments in den Leberzellen eine Vergrößerung des Durchmessers der Mitochondrien und ebenfalls eine Vergrößerung der Cristae mitochondriales. Für eine Neusynthese des Enzyms sprach auch die Tatsache, daß die $\delta$-Aminolävulinsäure-Synthetase in Inkubaten isolierter Mitochondrien mit löslichkeitsfördernden $\mathrm{Zu}-$ sätzen nicht direkt aktiviert werden konnte. Mit grundlegenden Untersuchungen brachte dann GranICK (1, $62,63)$ den Beweis, daß bestimmte chemische Fremdstoffe, Pharmaka und Sexualhormone, die im Tierexperiment und teilweise auch beim Menschen die chemischen Zeichen einer Porphyrie hervorrufen oder eine hepatische Porphyrie (64) klinisch exacerbieren können, die Porphyrinsynthese in der Leberzelle im Sinne einer Derepression des limitierenden Enzyms stimulieren. Darüberhinaus zeigten in vivo Experimente an Hühnerembryonen (vgl. S. 140), daß Lebermitochondrien, die 24 Stdn. nach einmaliger Applikation von $3 \mathrm{mg}$ Allylisopropylacetamid (1) isoliert wurden, achtmal mehr. $\delta$-Aminolävulinsäure gegenüber Kontrollansätzen synthetisierten, wenn sie mit Succinat und Glycin als Substraten inkubiert wurden.

Den Anstieg der Porphyrinsynthese in dem in vitro System primärer Hühnerembryo-Leberzellkulturen hat GranICK in den meisten Experimenten fluoreszenzmikroskopisch an Deckglas-Kulturen beurteilt (1). Wie aus zusätzlichen fluorometrischen Analysen von Extrakten (1) der Kulturen (Zellen und Medium) hervorging, waren die Porphyrine in mit Allylisopropylacetamid induzierten Kulturen nach einer Inkubationszeit von $22 \mathrm{Stdn}$. etwa $100 \mathrm{fach}$ erhöht. In den eigenen Experimenten (Abb. 2) stieg Protoporphyrin unter der Einwirkung stark induzierender Pharmaka in der Zellkultur um das 20- bis 30 fache an. Summiert man jedoch den Anstieg von Proto-, Kopro- und Uroporphyrin nach Induktion durch Substanzen wie Meprobamat, DDC oder Methyprylon in denjenigen Konzentrationen, welche die Porphyrine nach 20 bis 24 Stdn. Inkubation erreichten (37) und berücksichtigt dazu noch die Anteile der von der Synthesesteigerung ebenfalls betroffenen Porphyrine mit drei, fünf, sechs und sieben Carboxylgruppen, die hier 20 bis $25 \%$ der Gesamtsynthese einnahmen, so ergibt sich eine 80 fache Erhöhung der Porphyrinsynthese. Eine Übereinstimmung. mit den Befunden von Grantck (1) zeigt sich weiterhin im zeitlichen Verlauf der Porphyrinsynthese nach Applikation des Induktors und in der Reversibilität der Induktion, die dadurch nachgewiesen wurde, indem man das Medium zu einem Zeitpunkt zwischen drei bis neun Stdn. nach Zugabe der Substanzen abzog und durch frisches ersetzte. Wechselte man bei einer mit einem Induktor beschickten Kultur das Wuchsmedium erst nach neun Stdn., also zu einem Zeitpunkt, in dem die Porphyrinsynthese bereits steil anstieg (37), betrug die Porphyrinkonzentration nach 24 Stdn. nur die Hälfte gegenüber einer Kultur, die die induzierende Substanz. 
während der gesamten Inkubationsperiodc über $24 \mathrm{Stdn}$. cnthielt. Obwohl die noch in Suspension befindlichen Zellen dirckt nach Aussaat in die Zellkulturschale induziert werden konnte, erwies es sich als zweekmäßig, die porphyrogenen Substanzen crst nach 24 Stdn. bei einem Mediumwechsel hinzuzugeben, da

1. durch zwischenzeitliche mikroskopische Kontrollen die Qualität der Zellkultur beurteilt verden muß und

2. dic Induzierbarkcit der am Glas befindlichen Zellschicht 12 bis 24 Stdn. nach Ansetzen der Kulturen am besten ist.

Granick (1) fand in den in Kultur gezüchteten und induzierten Leberzellen $80 \%$ Koproporphyrin. Der Rest bestand aus Di- und Tricarboxyporphyrinen. In den hier vorliegenden Untersuchungen (s. Ergebnisse, S. 137 und 139) dominierte die Protoporphyrinsynthese gegenüber dem Auftreten anderer Porphyrine sowohl im zcitlichen Verlauf der Inkubation als auch am Ende der Kultivierung in summa. Die Synthese von Protoporphyrin in der I.cberzellkultur ist ein Maßstab für die Intensität des Induktionsprozesses (37). Protoporphyrin bildete den größBten Anteil der Porphyrine in den Zellen, die unter Meprobamat nach 24 Stdn. insgesamt $70 \%$ der gesamten sy'nthetisierten Porphyrine an das Medium abgegeben hatten.

Analog dem Experiment in der Leberzellkultur, wo infolge einer forcierten Synthese Protoporphỵrin gegenüber höher carboxylierten Porphyrinen überwog, wurde ïber relativ hohe Konzentrationen von Protoporphyrin in der Leber des Versuchstieres bei experimenteller Porphyrie schon mehrfach berichtet. SCHMID und Mitarbeiter $(65,66)$ fanden in der Leber mit Sedormid vergifteter Kaninchen fünf- bis achtmal mehr Protoporphyrin gegenüber Kopro- und Uroporphyrin. Ebenfalls wurde in Leberhomogenaten mit DDC bchandelter Meerschweinchen 90 bis 95\% Protoporphyrin festgestellt; der Rest war Koproporphyrin (56). In ähnlichen Experimenten mit Mäusen, denen DDC oder 2-Allyl-2isopropylacetamid verabrcicht wurde, zeigte sich, daB die Leber unter den Bedingungen der experimentellen Porphyric vorwiegend Protoporphyrin synthetisierte (52), das in einigen Fällen eine mehr als 10 fache Konzentration gegenüber Koproporphyrin erreichtc. Dagegen lag der Uroporphyringchalt erheblich niedriger. Der Verteilungstyp der Porphyrine (52) entspricht im Prinzip et wa demjenigen, wie er in eigenen Induktionsversuchen an Leberzcllkulturen mit stark induzierenden Substanzen nach 12 Stdn. (37) und mit weniger efficktiven Substanzen (z. B. Resochin, Sulfonamiden, Chloramphenicol, Griscofulvin; Östradiol) nach $24 \mathrm{Stdn}$. Inkubation vorlag. Auch die Verabrcichung von Griseofulvin an jungen Ratten führte zu einer Uberproduktion von Protoporphyrin in der Leber und im Knochenmark $(67,68)$. Außerdem war bei einem $P_{n-}$ tienten, der über mehrere Monate Griseofulvin eqrhalten hatte, der hepatozclluläre Gehalt an Protoporphyrin in dem durch Leberbiopsie gewonnenen Material crhöht (69). Diese Befundc zeigen, dal3 die durch Fremdchemi- kalien induzierte Porphyrinsynthese in der Leberzclle in vivo und in vitro auffallend parallele Eigenschaften aufweist. Aus den Zeitstudien der Leberzellkulturexperimente (37) und aus den Ergebnissen der in vivo Versuche mit Sedormid (70) stellt sich die Frage, warum das Endprodukt der Porphyrinsynthese, Protoporphyrin, zuerst ansteigt. Eine Hemmung der $\delta$-Aminolävulinsäure-Dehydratase-Aktivität im Leberhomogenat durch Protoporphyrin ist vermutet worden (52). Burnham und Lascellls (16) berichten über einen hemmenden Einfluß von Protoporphyrin auf die $\delta$-Aminolävulinsäure-Synthese in Präparationen der Synthetase aus Extrakten von Rhodopseudomonas sphaeroides. Nach in vitto Experimenten (37) scheint eine solche Regulation in der Leberzelle nicht zu existieren, da ja erst dann, wenn dic Konzentration von Protoporphyrin erheblich anstieg, Kopro- und später auch Uroporphyrin in größerer Menge gebildet wurden. Demzufolge ist hier eher an eine feedback-Hemmung auf die dem Reaktionsprodukt jeweils vorgeordneten Enzyme zu denken.

Mit Hämin, besonders in Konzentrationen zwischen 10 und $100 \mu \mathrm{M}$, konnte die durch Pharmaka (Abb. 2) und Steroide (Abb. 3) ausgelöste Erhöhung der Porphyrinsynthese weitgehend unterdrückt werden. Der Befund steht im Einklang mit der Arbeitshypothese (1), daß Häm als Corepressor eines Repressorsystems in die Kontrolle über die Bildung der $\delta$-Aminolävulinsäure-Synthetase eingreift. Da Protohäm dic Tetrapyrrolsynthese bei Bakterien sowohl durch feedback-Repression als auch durch Inhibition kontrolliert $(6,16,71)$, sind prinzipiell analoge Regelmechanismen der Tetrapyrrolsynthese für sämtliche Zelltypen, die über dic Fähigkeit zur Hämoprotcinsynthese aus niedermolekularen Bausteinen verfügen, zu postulieren. Analog der Beobachtung bei Bakterion (16) wurde in Lebermitochondrien von Ratten, denen zur Induktion der Synthetase Allylisopropylacetamid injiziert worden war, eine negative feedback-Kontrolle der $\delta$-Aminolävulinsäure-Synthetaseaktivität durch Häm gcfunden (18).

Dic vollständige Unterdrückung der mit Pharmaka und Steroiden stimulierbaren Porphyrinsynthese in Leberzellkulturen durch Inhibitoren der Nuclcinsäure- und Proteinsynthese, wie Actinomycin D, Mitomycin C und Puromycin in geeigneten Konzentrationen, stellt einen indirckten Bewveis dar, da (3 die Wirkung der incluzicrenden Substanzen auf dic $\delta$-Aminolävulinsäure-Synthetasc nicht auf einer Änderung der Konformation als allosterischer Übergang am Enzymprotein beruht, sondern, daß sic eine Neusynthese des Enzyms anregen. So wircl die erhöhte Bildung von Porphyrinen als Folge cincr Dercpression derjenigen Enzy'msynthese crklärt, die auch im physiologischen Zustand die Quantität nachfolgender anabolischer Synthesesquenzen der betreffenden Stoffwechselkettc limiticrt. Dic Resultate von Tscrumy und Mitarbeitern (10), die im Lebcrzylinder ciner an akuter intermittierender Porphyric crkrankten Patientin cine 7- bis 14 fach erhöhte Aktivitait der $\delta$ Aminolävulinsäure-Synthetase nachwieson, stïtzen die Hypothesc, daß dic $\delta$-Aminolävulinsäure-Synthetnse 
physiologischerweise in der Leberzelle durch eine Endprodukt-Repression kontrolliert wird.

Mehrere Untersucher fanden, daß die Katalaseaktivität in der Leber bei experimenteller Porphyrie, die am Xersuchstier durch DDC $(52,72)$ oder Sedormid $(66,70)$ hervorgerufen wurde, und in der Leber des Menschen bei hepatischer Porphyrie (72) abfällt $(52,66,70,72)$. Gleichzeitig damit waren der Sauerstoffverbrauch und die Glycin-2-C-Oxydation im Leberhomogenat herabgesetzt (72). Dagegen ging der Gehalt an Katalase in den peripheren Erythrocyten nach Gabe von Sedormid nicht zurück (70). Gleichzeitig mit dem frühen Abłfall der Katalase nach Sedormid stiegen die Proto- und Koproporphyrinkonzentrationen in der Leber an, während die Konzentrationen von Uroporphyrin und Porphobilinogen erst später anstiegen, wenn die Katalaseaktivität bereits niedrigere Werte erreicht hatte (70). Die auf Abbildung 6 dargestellte Verminderung der Protohäm- und Erhöhung der Protoporphyrinkonzentration im Verlaufe eines Zellkulturexperiments korreliert sowohl mit diesen Befunden (70) als auch mit den Ergebnissen von Ginsburg und Dowdle (72), die in der Leber mit DDC vergifteter Ratten dieselbe simultane und umgekehrt proportionale Änderung der Konzentrationen von Protoporphyrin und Katalase feststellten, wobei sich in einem neun Tage dauernden Experiment die Kurven des Katalaseabfalls und Protoporphyrinanstiegs am 4. Tag kreuzten, wie der Abfall des Häms und Anstieg des Protoporphyrins im Leberzellexperiment nach 10 Stdn. (Abb. 6). Die Differenz zwischen den Ergebnissen in vivo und in vitro besteht jedoch darin, $\mathrm{da}$ ' der Hämgehalt in den Kontrollen der Zellkulturexperimente im Verlauf der Inkubation noch stärker zurückging. Die Veresterung der Tetrapyrrole erfaßt sämtliches in der Zelle nicht kovalent gebundenes Protohäm (s. Methodik). Deshalb wird angenommen, da $B$ der Rückgang der Konzentration des Protohäms mit einer Abnahme der Katalase bereits unter den Kulturbedingungen der Leberzellinkubation erfolgt und hier kein spezifischer Effekt des Pharmakons ist. Hingegen erhielt die mit Meprobamat induzierte Kultur $80 \%$ mehr Protohämin als die Kontrolle. Auf die Porphyrinsynthese schwächer wirkende Substanzen führten jedoch nicht zu einer Erhöhung von Protohämin in den Leberzellkulturen. Verschiedene in vivo Versuche zeigten, daß die Hämsynthese in der porphyrischen Leberzelle erhöht ist. In der Leber Sedormidvergifteter Ratten war die "Leber-Hämatinfraktion“ gegenüber dem Normalbereich um $75 \%$ angestiegen $(66,70)$. Andere Autoren fanden eine größere ${ }^{59} \mathrm{Fe}-$ Utilisation der Leber von Mäusen, denen 2-Allyl-2isopropylacetamid injiziert worden war (52). Dagegen ändert sich der Einbau von ${ }^{59} \mathrm{Fe}$ in das Häm der Leber von mit DDC behandelten Mäusen nicht (52). Im Zusammenhang mit Untersuchungen über die Fettsäuresynthese bei experimenteller Porphyrie stellten LABBE und Mitarbeiter (53) fest, daß in der porphyrischen Leber sowohl der Einbau von ${ }^{50} \mathrm{Fe}\left({ }^{50} \mathrm{FeCl}_{3}\right)$ als auch von Succinat- $\left[2,3-{ }^{14} \mathrm{C}\right]$ und Acetat- $\left[2-{ }^{14} \mathrm{C}\right]$ in Häm er- höht ist. Parallel dazu stieg der Einbau der Vorläufer in Fettsäuren aus Acetat um 100\% und aus Succinat um $300 \%$ an. Über einen Anstieg des Hämenzyms Tryptophan-Pyrrolase ${ }^{2}$ ) in der Leber von Ratten nach Gabe von Sedormid wurde ebenfalls berichtet (73). Zusammenfassend geht aus den Daten über die Hämsynthese nach Applikation porphyrinogener Fremdstoffe in vivo und in vitro hervor, daß ihre Wirkung auf die Porphyrinsynthese weiterhin zu einer höheren Hämsynthese führen kann.

Wie vorausgehend besprochen wurde, steht zur Erklärung des Wirkungsprinzips porphyrinogener Substanzen eine Arbeitshypothese zur Verfügung, die aus den Vorstellungen über die Gen-abhängigen Regulationen der Proteinsynthese entwickelt wurde und die biochemischen Manifestationen experimenteller und angeborener Porphyrien auf einen einzigen Mechanismus zurückführt: Verlust der Kontrolle über die Bildung des für eine Kette von Reaktionsabläufen limitierenden Enzyms. Im Gegensatz dazu liegen über die Einflüsse auf die Synthese aus $\delta$-Aminolävulinsäure nur Einzelfakten vor, die allerdings zeigen, daß Steuerungsprozesse auch in diesem Abschnitt der Synthese vorhanden sein müssen. Aber ein einheitliches Konzept über den Regelmechanismus, der die Synthese von der $\delta$-Aminolävulinsäure bis zum Häm umfaßt, ist noch nicht erarbeitet worden. Die rapide Zunahme von Porphyrinen aus zugesetzter $\delta$-Aminolävulinsäure (s. S. 139) bestätigt zunächst nur, daß die an diesen Reaktionen beteiligten Enzyme in der Leberzelle in nicht-begrenzender Menge vorliegen. Aus einer Studie über die Hämsynthese aus $\delta$-Aminolävulinsäure an den Erythrocyten des Menschen (74) ging hervor, daß dieser Synthesezweig multifaktoriell beeinflußt wird. Eine negative feedbackKontrolle der $\delta$-Aminolävulinsäure-Dehydratase durch Häm wurde an den Erythrocaten des Menschen (20) und bei Bakterien (15) festgestellt. GranICK und URATA (56) berichteten, daß die bei hoher $g$-Zahl gewonnenen Überstände des Leberzellinhalts von Tieren, denen DDC appliziert wurde, $25 \%$ mehr Porphobilinogen aus $\delta$-Aminolävulinsäure synthetisierten und $57 \%$ mehr Porphobilinogen in Porphyrine konvertierten als die gleiche Zellfraktion von Kontrolltieren. Dagegen fanden sie keine Unterschiede in der Aktivität der Koproporphyrinoxydase zwischen Lebermitochondrien behandelter und gesunder Tiere (56). Demzufolge mußten die für die Synthese von Porphobilinogen und Koproporphyrinogen kompetenten Enzyme in den Leberzellüberständen der „DDC-Meerschweinchen“ in erhöhter Aktivität vorhanden gewesen sein. Unter der alleinigen Voraussetzung, daß die Enzyme dieses Syntheseabschnittes in nicht-limitierender Menge gebildet werden, sollten in beiden Inkubaten mit demselben Substratangebot keine Differenzen in der Syntheserate von Porphobilinogen und Porphyrinen eintreten. Eine erhöhte Aktivität der $\delta$-Aminolävulinsäure-Dehydratase in der Leber von Kaninchen wurde allerdings nach Applikation von Sedormid beschrieben $(75,76)$. ONISAWA und LABBE zeigten (77), daß die Dehydratase-Aktivität in der Leber 
durch die Konzentration der $\delta$-Aminolävulinsäure determiniert und wahrscheinlich direkt durch das Substrat aktiviert wird. Unter Einschluß dieser Beobachtungen bieten sich für den in Abbildung 5 wiedergegebenen Befund einer Mehrsynthese von Porphyrinen aus zugesetzter $\delta$-Aminolävulinsäure unter der Einwirkung bestimmter Pharmaka folgende Erklärungsmöglichkeiten an:

1. Es handelt sich um einen Effekt des Pharmakons analog demjenigen nach in vivo Induktion der Porphrrinsynthese $(56,75,76)$, der wahrscheinlich in einem adaptiven Anstieg der $\delta$-Aminolävulinsäure-Dehỵdratase besteht.

2. Das Pharmakon wirkt direkt auf die einzelnen Enzyme (52).

3. Beide Wirkungen können sich an verschiedenen Stellen der Synthesekette manifestieren oder auch an einer Reaktionssequenz miteinander interferieren.

Für die letzte Annahme spricht der Befund, daß in der Leberzellkultur sowohl unter Zusatz von Meprobamat als auch von Ätiocholanolon um 30\% weniger Protoporphyrin aus $\delta$-Aminolävulinsäure synthetisiert wurden als in Kontrollkulturen, wobei sich diese Differenz allerdings erst in der zweiten Hälfte der Inkubationszeit, also nach 12 Stdn., entwickelte. Auf welche Weise das Pharmakon oder Steroid unter den Bedingungen des Zellkultur-in-vitro-Systems Aktivitätsänderungen der Koproporphyrin-Oxydase herbeiführen können, bleibt noch ungeklärt.

Die Kulturen mit $\delta$-Aminolärulinsäure enthielten nur um 40 bis $60 \%$ mehr Häm im Vergleich zur Kontrolle, obwohl eine 100 fach höhere Konzentration an Protoporphyrin aus zugesetzter $\delta$-Aminolāvulinsäure entstand. Diese Protoporphyrinkonzentration lag jedoch noch zwei Zehnerpotenzen unter dem $\mathrm{Km}$-Wert von Protoporphyrin für die Häm-Synthetase, wie er von Bortomley (21) in den Knochenmarkzellen des Menschen ermittelt wurde.

\section{Klinische Aspekte}

Von einer großen $Z$ ahl verschiedener Pharmaka einschließlich Chemotherapeutika und Antibiotika (1, 41, $43,78,79,80,81)$ ist bekannt, daß sie bei Genträgern einer hepatischen Porphyrie eine akute Symptomatik und bei Gesunden sowie im Tierversuch einen Anstieg der Porphyrinsynthese in der Leber und eine Porphyrinurie hervorrufen können. So erwiesen sich in tierexperimentellen Untersuchungen besonders folgende Substanzen als porphyrinogen: Pharmaka der Sedormid- und Barbituratgruppe $(41,43,52,53,65,66,70$, $79,82,83,84,85), 3,5$-Dicarbäthoxy-1,4-dihydrocollidin $(52,56,60,61,72,84,86,87)$, Hexachlorbenzol $(79,88$, $89)$ und niedriger chlorierte Derivate (90), Griseofulvin $(67,68,69,91,92)$ und 6-Mercaptopurin (93). Beim Menschen sind Störungen der Porphyrinsynthese vorwiegend nach Barbituraten (40, 43, 79, 94), Sulfonamiden $(40,78,79,94,95,96)$, Griseofulvin $(69,79,97)$, Chloroquin $(94,98)$, Hexachlorbenzol $(79,99)$, Äthanol
$(40,79,94,100,101,102)$ und Blei $(40,103,104,105)$ aufgetreten. Eine detaillierte Darstellung der sog. toxischen Störungen des Porphyrinstoffwechsels befindet sich in der Monographie von BRUGSCH (40).

Die häufige Koinzidenz von Menstruation und Gravidität und der klinischen Manifestation einer hepatischen Porphyrie (43, 106, 107, 108, 109, 110, 111, 112) weist auf pathogenetische Beziehungen zwischen den weiblichen Sexualhormonen und der Hämsynthese hin. Es wurde darüber berichtet, daß sowohl die Verabreichung von Progesteron (113) als auch von Östrogenen eine akute intermittierende Porphyrie exacerbieren können (114). Äthinylöstradiol (114) und Diäthylstilböstrol (115) führten bei Patienten mit einer akuten intermittierenden Porphyrie zu einer signifikant erhöhten Ausscheidung von $\delta$-Aminolävulinsäure und Porphobilinogen (114) sowie von Uroporphyrin (115). Unter der Malignom-Therapie nicht-porphyrischer Patienten mit Diäthylstilböstrol kam es nicht zu einer erhöhten Ausscheidung von Porphyrinvorstufen und Porphyrinen im Urin (115), im Gegensatz zur Behandlung von Malignomen mit Östrogenen bei einer Porphyria cutanea tarda $(110,116)$. Dagegen ist bei Gesunden eine primäre Störung der Porphyrinsynthese durch orale Kontraceptiva, die zu einem erhöhten Vorkommen von $\delta$-Aminolävulinsäure und Koproporphyrin der Isomerenreihe I im Urin führten (117), nicht bewiesen.

Aus der vergleichenden Betrachtung klinischer, tierexperimenteller und aus Leberzellkulturen (Abb. 2 bis 4) erhaltener Ergebnisse folgt, daß sowohl porphyrinogene Pharmaka als auch Steroide wie Progesteron, Östrogene und stereoisomere Steroidmetabolite der $5 \beta$-H-Reihe (cis-Stellung der A:B-Ringe) im Prinzip gleichartig auf den Porphyrinstoffwechsel wirken, indem sie über eine Induktion der $\delta$-Aminolärulinsäure-Synthetase die Gesamtsynthese stimulieren (11). Auf welche Weise es aber zu den der klinischen, vorwiegend neurologischen (118) Symptomatik zugrunde liegenden pathophysiologischen Störungen bei der akuten intermittierenden Porphyrie kommt, ist noch unklar. Eine von DE Matteis und Rinington (119) entworfene Hypothese versucht, diese Störungen auf eine verminderte Synthese von Acetylcholin zurückzuführen, die als Folge einer stärkeren Metabolisierung des Glycins über den SHEMIN-Zyklus (120) entstehen soll, wobei dann weniger aktives Acetat für die Bildung des Acetylcholins bereit stehen würde.

Die Leberzellkultur als ein permanent kontrollierbares und unter identischen Bedingungen mit relativ geringen Variationen reproduzierbares in-vitro-System ist geeignet, Substanzen in ihrer Wirkung auf die Porphyrinsynthese zu erkennen und zu prüfen. $\mathrm{Da}$ neben den erwähnten Pharmaka auch Pyrazolidinderivate ein Porphyrie-Syndrom provozieren können (78), haben wir p-Hydroxy-phenylbutazon (Abb. 2), einen Metaboliten des Phenylbutazons, in der Leberzellkultur näher untersucht. Die Substanz führte zu einer signifikanten Erhöhung der Porphyrinsynthese (121). Obgleich das Ergebnis nicht direkt auf den Stoffwechsel der Leber des 


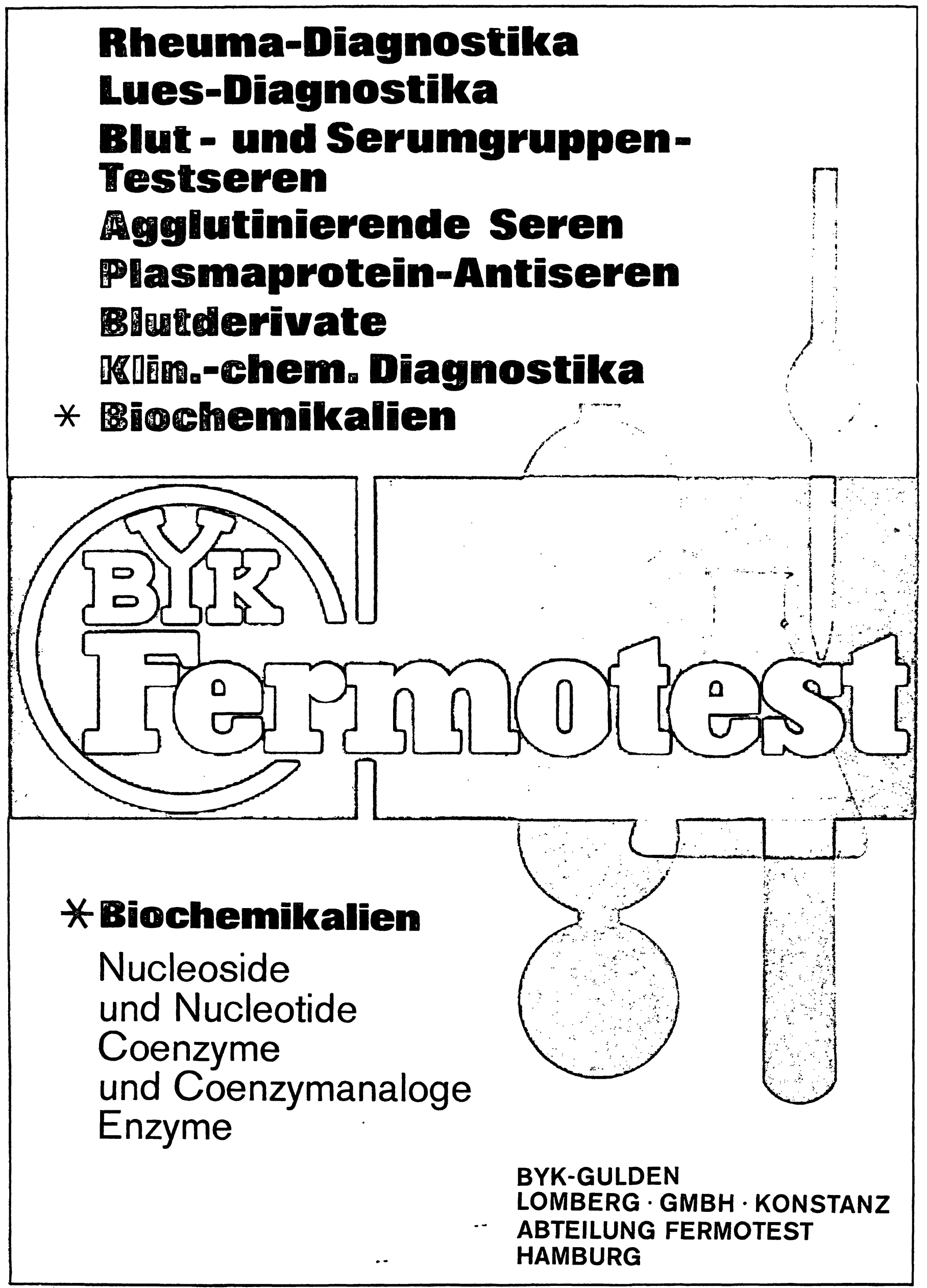




\section{ALOIS J. BEUREN}

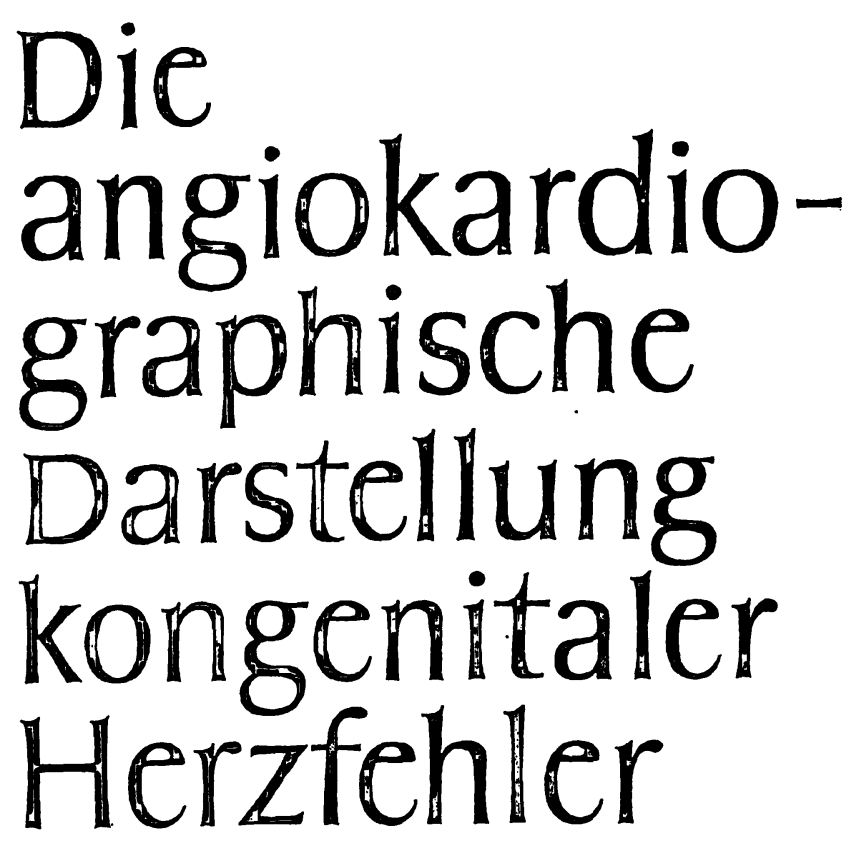

EIN ATLAS

von ALOIS J. BEUREN

Dr. med., ao. Prof. mit Lehrstuhl f. pädiatrische Kardiologie u. Leiter der kardiologischen Abt. der Universitäts-Kinderklinik Göttingen

mit Geleitworten von

Prof. Helen B. Taussig, M. D.

und Prof. Dr. med. G. Joppich

Quart

Mit 285 Abb. in 459 Einzeldarst. XVI, 312 Seiten.

1966. Ganqleinen DM 175,-

\section{Zentralblatt für Chirurgie}

Der geübte Betrachter wird Freude an dem Studium von Einzelheiten haben, der Anfänger eine gute Information finden. - Zusammenfassend muß man feststellen, daß dieses vom Verfasser konsequent auf Grund großer persönlicher Erfahrung aufgebaute und vom Verlag hervorragend ausgestattete Buch allen Chirurgen empfohlen werden kann, die der operativen Kardiologie nahestehen.

\section{ZENTRALBLATT FÜr DIE}

\section{GESAMTE RADIOLOGIE}

Alles in allem kann gesagt werden, daß es bisher kein Werk gibt, in welchem die angiokardiographische Darstellung angeborener Herzfehler so lückenlos, so verständlich und mit soviel persönlicher Erfahrung beschrieben worden ist. Die ganz hervorragende Ausstattung tut ein übriges, um es dem Ref: leicht zu machen, jeder radiologischen Klinik, jedem radiologischen Institut, aber auch jedem Radiologen überhaupt, die Anschaffung dieses Buches zu empfehlen.

\section{WALTER DE GRUYTER \& CO - BERLIN 30}


Menschen übertragen werden kann, ist das Pharmakon dennoch als eine potentiell porphyrinogene Substanz zu beurteilen. Auch mit Progesteron und Östradiol wurde in Leberzellkulturen eine stimulierende Wirkung auf die Porphyrinsynthese gefunden (122), die mit den klinischen Beobachtungen über die durch Östrogene und Progesteron induzierte Manifestation hepatischer Porphyrien übereinstimmt. In der Leberzellkultur wirkte Östradiol schwächer als Progesteron.

Die erhöhte Aktivität der $\delta$-Aminolävulinsäure-Synthetase in der Leber des Menschen bei akuter intermittierender Porphyrie, bei experimenteller Porphyrie und in den primären Hühnerembryo-Leberzellkulturen lassen einen gemeinsamen Wirkungsmechanismus in der Hämsynthese erkennen. Die Wirkung der Fremdstoffe auf die Porphyrinsynthese des Laboratoriumstiers und beim Menschen in zeitlicher und quantitativer Hinsicht zeigt jedoch artspezifische Unterschiede, die wahrscheinlich mit dem Metabolismus eines bestimmten Pharmakons in der betreffenden Spezies zusammenhängen (47).

Induktion der Porphyrinsynthese und arzneimittelabbauender Enzyme

Die Induktion der Porphyrinsynthese wird wie die Induktion arzneimittelabbauender Enzyme durch völlig verschiedene chemische Fremdstoffe und auch Steroide (123) in der Leberzelle ausgelöst. Die induzierenden Substanzen sind lipoidlöslich. Beide Induktionsvorgänge sind unspezifische Prozesse. Im folgenden werden noch weitere, zwischen den beiden Reaktionen übereinstimmende Parallelen hervorgehoben:

1. Phenobarbital, das vorwiegend in den Untersuchungen über die Induktion arzneimittelabbauender Enzyme eingesetzt wurde $(46,47,59)$, ruft ebenfalls eine experimentelle Porphyrie hervor (85). Es ist anzunehmen, daß auch andere, vorwiegend die arzneimittel-metabolisierenden Enzyme induzierenden Pharmaka ebenfalls die Porphyrinsynthese induzieren. Reziproke Wirkungsverhältnisse auf beide Reaktionen liegen möglicherweise dann vor, wenn ein vorwiegend porphyrinogenes Pharmakon auch die arzneimittelabbauenden Enzyme mitinduziert. Hinweise auf die Induktion arzneimittelabbauender Enzyme durch Substanzen .wie Meprobamat, Glutethimid und Phenylbutazon, die sich in den Leberzellkulturversuchen als stark porphyrinogen erwiesen, gibt RemMer $(47,124)$.

2. Sowohl bei experimenteller Porphyrie als auch bei der Induktion der arzneimittelabbauenden Enzyme kommt es zu einer Stimulation des Leberwachstums und zur Hypertrophie der Leber $(47,49,50,52,53,54,55$, $58,67,68$ ).

3. In beiden Prozessen kommt es zu einer Erhöhung der RNA $(54,124,125)$ und der Lipoide $(50,54,124)$. Die mikrosomalen Phosphatide der Leberzelle stiegen sowohl bei den mit Phenobarbital (124) als auch bei den mit Allylisopropylacetamid (58) behandelten Ratten an. Mit Allylisopropylacetamid war eine hepatische Porphyrie erzeugt worden (58).
4. Beide Prozesse führen zu einer Hypertrophie der glatten Membranen des endoplasmatischen Retikulums $(49,57,58,59,126)$.

5. Beide Induktionsvorgänge können durch Actinomycin D und Puromycin (127) unterdrückt werden (126). Bei einem ausgelösten Induktionsprozeß geht dann, wenn der Induktor aus dem Experiment wieder entfernt wird, der Anstieg der jeweiligen Syntheseprodukte, Porphyrine (1) oder Cytochrom P-450 (128), wieder zurück.

6. Sowohl in der porphyrischen Leber $(53,68)$ als auch nach Phenobarbitalbehandlung (124) wird mehr Protohämin gefunden. Die Analysendaten können nicht direkt verglichen werden, da sie mit verschiedenen Methoden gewonnen wurden. ReMmer und Mer ker (124) bestimmten Cytochrom $b_{5}$. Mit Meprobamat, Glutethimid, Methyprylon und DDC induzierte Leberzellkulturen enthielten ebenfalls mehr Protohämin. Nach den Befunden von Estabrook, Cooper und RosenTHAL (129) ist an der Hydroxylierung der Pharmaka (130) das von Klingenberg (131) in den Mikrosomen der Leberzelle entdeckte Cytochrom P-450 maßgeblich beteiligt $(48,132)$. Über das Vorkommen von Cytochrom P-450 in den Mikrosomen verschiedener Gewebe und seine Funktion in den Hydroxylierungsreaktionen ist von Strittmatter kürzlich referiert worden (133). Cytochrom P-450 trägt Protohäm als prosthetische Gruppe (134). Nach Applikation von Barbituraten kommt es 24 bis $48 \mathrm{Stdn}$. später zu einem erheblichen Anstieg des Cytochrom P-450 in der Mikrosomenfraktion der Leberzelle $(48,132)$. Da ein Pharmakon als Stimulus für seine eigene Destruktion wirkt (134), indem es eine Mehrsynthese der mikrosomalen „mixed function oxidases" (136) anregt, müßte besonders für den Anstieg von Cytochrom P-450 mehr Häm zur Verfügung stehen. Dem Prozeß würde eine Überproduktion von Häm vorangehen, wenn eine mit den mikrosomalen Reaktionsabläufen verbundene de novo Synthese der $\delta$-Aminolävulinsäure-Synthetase und damit eine Steigerung der Porphyrinsynthese stimuliert werden. Protohämin wird aber nicht nur für das CO-bindende Pigment des Hydroxylasen-Systems, sondern auch für das Cytochrom $b_{5}$ benötigt, dessen Konzentration im glatten endoplatischen Retikulum der Leberzelle nach Phenobarbital um das Dreifache anstieg (124). Die Idee von GrANICK (1), daß infolge der Induktion der $\delta$-Aminolävulinsäure-Synthetase mehr Häm für hydroxylierende Hämoproteine gebildet werden könnte, erhält durch den Nachweis höherer Hämkonzentrationen in den induzierten Leberzellkulturen (Abb. 6) eine experimentelle Stütze.

Eine simultane Induktion der $\delta$-AminolävulinsäureSynthetase und arzneimittelabbauender Enzyme durch Allylisopropylacetamid oder Barbiturate würde die Hypertrophie der glatten Membranen des endoplamatischen Retikulums bei experimenteller Porphyrie (58) erklären: Der Anstieg der mikrosomalen NADPHCytochrom-c-Reduktase (123) bei experimenteller Porphyrie $(137,138)$ spricht für das Vorkommen einer 
gleichzeitigen Induktion der $\delta$-Aminolävulinsäure-Synthetase und mikrosomaler, an der Metabolisierung von Pharmaka beteiligter Enzyme. Die Rolle der NADPHCytochrom-c-Reduktase als Komponente der oxydativen Demethylierung haben Orrenius und ERNSTER (48) nachgewiesen, wobei die Substrat(Pharmaka)induzierte Aktivierung des Enzyms über eine mRNASynthese läuft (48).

Nach neueren elektronenmikroskopischen Untersuchungen (58) wiesen die Mitochondrien der Leberzellen bei experimenteller hepatischer Porphyrie keine Veränderungen auf. $\mathrm{Da}$ es nach Applikation porphyrinogener Substanzen zu einer Induktion der $\delta$-Aminolävulinsäure-Synthetase kommt, die für diese molekulare Störung charakteristisch ist, stellt sich die Frage, ob eine Beziehung zwischen der Proliferation des endoplasmatischen Retikulums und der Mehrsynthese der $\delta$-Aminolävulinsäure-Synthetase besteht. Die Autoren (58) vermuten, daß die $\delta$-Aminolävulinsäure-Synthetase möglicherweise außerhalb der Mitochondrien am endoplasmatischen Retikulum gebildet, danach zum Mitochondrium transportiert wird und in die Organelle eintritt. Das Vorkommen eines solchen Proteintransports vom 'endoplasmatischen Retikulum zum Mito- chondrium haben Kadenbach (139) sowie Pennial und Davidian (140) für das Cytochrom c beschrieben.

Aus den diskutierten Befunden über die Wirkung von Pharmaka auf die Porphyrinsynthese und die Synthese arzneimittelabbauender Enzyme resultiert, daß wahrscheinlich beide Induktionsprozesse, die von verschiedenen Genen und von verschiedener mRNA reguliert werden, miteinander gekoppelt sein können. So wie OrRentus und ERICSSON (126) zwei verschiedene Mechanismen für die Regulation der Enzym- und Membransynthese vorgeschlagen haben, die in vivo eng aufeinander abgestimmt sind, wird für die Derepression der Hämsynthese einerseits und die Induktion mikrosomaler Enzyme, wie insbesondere der Synthese von Cytochrom P-450 und der NADPH-Cytochrom-cReduktase, andererseits ein Konzept auszuarbeiten sein, das die Korrelation zwischen den beiden Mechanismen herstellt.

Die Zellkulturexperimente wurden in den virologischen Laboratorien des Hygiene-Instituts, dank des freundlichen Entgegenkommens von Herrn Dozent Dr. F. LehManN-Grube, durchgeführt.

\section{Literatur}

1. Gravick, S., J. biol. Chemistry 241,1359 (1966). - 2. JACOB, F. und J. Monod, J. Mol. Biol. 3, 318 (1961). - 3. Lwoff, A., Biological Order, M. I. T. Press, Cambridge, Mass. (1962). 4. Potrer, V. R., in: Advances in enzyme regulation, ed. by G. Weber, Pergamon Press Oxford-London-New York-Paris (1963), Vol. 1, S. 279. - 5. WIELAND, O., in: Molekularbiologie als Fundament der modernen Medizin, J. F. Lehmanns Verlag München (1967) S. 76. - 6. LAsCenles, J., Tetrapyrrole biosynthesis and its regulation, W. A. Benjamin. Inc., New York und Amsterdam (1964). - 7. LAscelles, J., in: Advances in microbial physiology, ed. by A. H. Rose and J. F. Wilkinson, Academic Press, London und New York (1968), Vol. II, S. 1. - 8. Doss, M., Biochim. biophysica Acta, Amsterdam 170, 461 (1968). - 9. Levere, R. D. und S. Granick, Proc. Nat. Acad. Sci. (USA) 54, 134 (1965). - 10. Tschudy, D. P., M. G. Perlroth, H. S. Marver, A. Collins, G. Hunter jr. und M. Rechcigl jr., Proc. Nat. Acad. Sci. (USA) 53, 841 (1965). - 11. Granick, S. und A. Kappas, J. biol. Chemistry 242, 4587 (1967). - 12. Kappas, A. und S. Granick, J. biol. Chemistry 243, 346 (1968). - 13. Levere, R. D., A. Kappas und S. Granick, Proc. Nat. Acad. Sci. (USA) 58, 985 (1967). - 14. LabBe, R. F., T. Kumurada und J. Onisawa, Biochim. biophysica Acta, Amsterdam 111, 403 (1965). - 15. Lascelles, J., J. gen. Microbiol. 23, 487 (1960). - 16. Burnham, B. F. und J. Lascelles, Biochem. J. 87, 462 (1963). - 17. KarIBIAN, D. und I. M. London, Biochem. Biophys. Res. Commun. 18, 243 (1965). - 18. Welland, F. und H. C. Schwartz, Clin. Research 14, 142 (1966). - 19. VAVRA, J. D., J. clin. Invest. 46, 1127 (1967). - 20. Calissano, P., D. Bonsignore und C. Cartasegna, Biochem. J. 101, 550 (1966). - 21. BotromLEy, S. S., Blood 31, 314 (1968). - 22. Doss, M., J. Chromatog. 30, 265 (1967). - 23. Doss, M., diese Z. 6, 498 (1968). - 24. Doss, M., Abstr. 5th Meeting Federat. of Europ. Biochem. Soc., Prag (1968) S. 118. - 25. Doss, M., Hoppe-Seyler's Z. physiol. Chem. 349, 1243 (1968). - 26. Doss, M., Klin. Wschr. 46, 731 (1968). - 27. LehMaNN-Grube, F., in: Virus- und Rickettsieninfektionen des Menschen, hrsg. von R. Haas und O. Vivell, J. F. Lehmanns Verlag Müncheń (1965) S. 30. - 28. Hanks, J. H. und R. E. Wallace, Proc. Soc. exp. Biol. (N. Y.) 71, 196 (1949). - 29. Wallis, C., R. T. Lewis und J. L. Melnick, Texas Rep. Biol. Med. 19, 194 (1961). - 30.
EAGLE, H., Science, Washington 130, 432 (1959). - 31. Doss, M. und U. BoDE, diese Z. 6, 383 (1968). - 32. Doss, M. und U. BODE, J. Chromatog. 35, 248 (1968). - 33. PorrA, R. J. und O. T. G. Jones, Biochem. J. 87, 181 (1963). - 34. FALK, J. E., Porphyrins and Metalloporphyrins, Elsevier, Amsterdam-IondonNew York (1964). - 35. SchlENker, F. S., N. A. TAyLOR und B. P. Kiefn, Amer. J. clin. Path. 42,349 (1964). - 36. Mauzerall, D. und S. Granick, J. biol. Chemistry 219, 435 (1956). - 37. Doss, M., FEBS Letters 2, 127 (1968). - 38. Doss, M. und H. Bürger, Hoppe-Seyler's Z. physiol. Chem. 348, 936 (1967). 39. Goldberg, I. H., Amer. J. Med. 39, 722 (1965). - 40. BRUGSCH J., Porphyrine, Johann Ambrosius Barth Verlag, Leipzig (1959). 41. SтICH, W., in: Nebenwirkungen von Arzneimitteln auf Blut und Knochenmark, hrsg. von R. Jürgens und J. Waldenström, Schattauer-Verlag, Stuttgart (1957) S. 36. - 42. STICH, W., in: Grundlagenforschung in ihrer Bedeutung für die Klinische Medizin, Heilmeyer-Symposium, hrsg. von W. Keiderling, Schattauer-Verlag, Stuttgart (1965) S. 67. - 43. Goldberg, A. und C. Rimington, Diseases of porphyrin metabolism, Charles C. Thomas Publisher, Springfield, Ill. USA (1962). - 44. Ciba foundation symposium on porphyrin biosynthesis and metabolism, ed. by G. E. W. Wolstenholme und E. C. P. Mrllar, J. \& A. Churchill LTD, London (1955). - 45. Rimington, C., Acta med. scand., Suppl. 445, 11 (1966). - 46. REMmER, H., R. W. EstaBRook, J. Schenkman und H. Grem, Naunyn-Schmiedebergs Arch. exper. Path. 259, 98 (1968). - 47. Remiser, H., Dtsch. Med. Wschr. 92, 2001 (1967). - 48. Orrenius, S. und L. Ernster, Biochem. Biophys. Res. Commun. 16, 60 (1964). - 49. Kunz, W., G. Schaude, W. Schmid und M. Siess, Proc. Europ. Soc. Study of Drug Toxic., Vol. VII, Rom (1966) S. 113. - 50. Kunz, W., G. Schaude, H. Schimassex, W. Schmid und M. Siéss, Proc. Europ. Study of Drug Toxic., Vol. VII, Rom (1966) S. 138. 51. Kunz, W., U. Gerbez und W. Schulz, Naunyn-Schmiedebergs Arch. exper. Path. 257, 298 (1967). - 52. OnisAwA, J. und R. F. LABBE, J. biol. Chemistry 238, 724 (1963). - 53. LABBE, R. F., Y. Hanawa und F. I. Lotrsfeldt, Arch. Biochem. Biophysics 92, 373 (1961). - 54. LotTsFeldt, F. I. und R. F. LABBE, Proc. Soc. exp. Biol. (N. Y.) 119, 226 (1965). - 55. TAdDEINI, L., K. L. Nordstrom und C. J. Watson, Metabolism, Baltimoore 13, 
691 (1964). - 56. Granick, S. und G. Urata, J. biol. Chemistry 238, 821 (1963). - 57. Remmer, H. und H. J. Merker, Klin. Wschr. 41, 276 (1963). - 58. Posalaki, Z. und T. Barka, J. Histochem. Cytochem. 16, 337 (1968). - 59. Orrenius, S., J. L. Ericsson und L. Ernster, J. Cell Biol. 25, 627 (1965). - 60. Solomon, H. M. und F. H. J. Pigge, Proc. Soc. exp. Biol. (N. Y.) 100, 583 (1959). - 61. Solomon, H. M. und F. H. J. Figge, Proc. Soc. exp. Biol. (N. Y.) 105, 484 (1960). - 62. Granick, S., J. biol. Chemistry 238, PC 2247 (1963). - 63. Granick, S., Ann. N. Y. Acad. Sci. 123, 188 (1965). - 64. Watson, C. J., dicse Z. 2, 25 (1964). - 65. Scrimid, R. und S. SchwatR\%, Proc. Soc. exp. Biol. (N. Y.) 81, 685 (1952). - 66. Scirmid, R., J. F. Figen und S. Schwartz, J. biol. Chemistry 217, 263 (1955). - 67. de MatteIs, F., Biochem. J. 98, 23c (1966). - 68. De Matreis, F. und C. Rimingron, Brit. J. Dermat. 75, 91 (1963). - 69. Watson, C. J., Porphyrin metabolism, in: Diseases of metabolism, ed. by G. Duncan, W. B. Saunders Company, Philadelphia und London (1965) S. 850. - 70. SCHMid, R. und S. SCHWARTZ, in: 1. c. 44, S. 196. -- 71. Doss, M., unveröffentlichte Ergebnisse. - 72. GinsburG, A. D. und E. B. Dowdle, S. Afr. J. Laborat. clin. Med. 9, 206 (1963). - 73. Greengard, P. und P. Feigelsos, Amcr. Chem. Soc. Abstracts, 18, 7C (1961). - 74. Herlmeyer, L., R. Clotren und L. Heilmeyer jr., Die Störungen der Bluthämsynthese mit besonderer Berücksichtigung der sideroachrestischen Anämien und erythropoetischen Porphyrien, Georg Thieme Verlag, Stuttgart (1964). - 75. Tancioni, A., H. A. Tigrer und M. Grinstern, Biochem. Pharmacol. 13, 1095 (1964). - 76. Grbsọ,, K. D., in: 1. c. 44, S. 27. - 77. ONISAWA, J. und R. F. LABBE, Biochim. biophysica Acta, Amsterdam 56, 618 (1962). - 78. Filippini, L., Dtsch. Med. Wschr. 91,959 (1966). - 79. Schmid, R., S. Afr. J. Laborat. clin. Med. 9, 212 (1963). - 80. Granick, S., J. Amer. Med. Ass. 190, 475 (1964). - 81. Strohmeyer, G., Münch. med. Wschr. 110, 1275 (1968). - 82. STrcH, W. und P. DeCKer, in: 1. c. 44, S. 254. - 83. Stich, W., Klin. Wschr. 36, 386 (1958). - 84. HAeger-Aronson, B., Acta pharmacol. (K'hvn) 18, 165 (1961). - 85. Talaan, E. L., J. D. Case, R. A. Nevé, R. F. LabBe und R. A. Aldrich, J. biol. Chemistry 212, 663 (1955). - 86. De Matreis, F. und B. E. Prior, Biochem. J. 83, 1 (1962). - 87. de Matteis, F., T. F. Slater und D. Y. Wang, Biochim. biophysica Acta, Amsterdam 68, 100 (1963). - 88. Caypbeli, J. A. H., S. Afr. J. Laborat. clin. Med. 9, 203 (1963). 89. OCKNer, E. K. und R. SChMID, Nature London 189, 499 (1961). - 90. Rimington, C. und G. Ziegler, Biochem. Pharmacol. 12, 1387 (1963). - 91. GAJDOS, A. und M.GAJDos-TöröK, Nature London 206, 297 (1965). - 92. Owens, C. W. I., Brit. J. Dermat. 76, 81 (1964). - 93. GajDos, A., in: 1. c. 42, S. 99. - 94. Rimington, C., Proc. roy. Soc. Med. 57, 511 (1964). - 95. SANdberg, C. G. und L. WetrerberG, Scand. J. clin. Iaborat. Invest. 20, 176 (1967). - 96. Vannotri, A., Porphyrins: their biological and chemical importance, Hilger and Watts, London (1954). - 97. Rimington, C., P. N. Morgan, K. Nichols, J. D. Everall und R. R. Davies, Lancet, London 1963/II, 318. - 98. SweENEY, G. D., S. J. Saunders, E. B. Dowdle und L. Eales, Brit. med. J. 1965/1, 1281. - 99. Peters, H. A., S. A. M. Johnson, S. Cam,
S. Orat., Y. Mürtü und T. Ergene, Amer. J. Med. Sci. 251, 314 (1966). - 100. SutherLAND, D.A. und C. J. Warson, J.S.aborat. clin. Med., S. Louis 37, 29 (1951). - 101. Watson, C. J., D. A. SutuserLAND und V. HAw KINSON, J. Laborat. clin. Med., S. Louis 37,8 (1951). - 102. Creutrztredr, W., K. Beck, R. Clotten und J. Branchi, Acta hepato-splenol. 13, 65 (1966). - 103. Chisholm, J. J., J. Pediatr., S. Louis 64, 174 (1964). - 104. Gutnin K, O., H. Kozrolowa und E. Kowalski, Lancet, London 1964/I, 1137. 105. Dagg, J. H., A. Goldberg, A. LochHead und J. A. Smith, Quart. J. Med., New Scrics XXXIV, 163 (1965). - 106. Hungr, F. B., Schweiz. med. Wschr. 97, 1498 (1967). - 107. Huber, F. B., Schweiz. med. Wschr. 96, 818 (1966). - 108. ZimmermanN, T. S., J. M. MCMillin und C. J. Watson, Arch. intern. Med. 118, 229 (1966). - 109. Hopmann, R., Dtsch. Mcd. Wschr. 93, 76 (1968). 110. VAIL, J. T., J. Amer. med. Ass. 201, 671 (1967). - 111. Watson, C. J., W. Runge und I. Bossenmaier, Metabolism, Baltimoore 11, 1129 (1962). - 112. Perlroth, M. G., H. S. Marver und D. P. Tschudy, J. Amer. med. Ass. 194, 1037 (1965). 113. Levit, E. J., J. H. Nodine und W. H. Perlopp, Amer. J. Med. 22, 831 (1957). - 114. Welland, F. H., E. S. Hellsan, A. Collins, G. W. Hunter und D. P. Tschudy, Metabolism, Baltimore 13, 251 (1964). - 115. Theologides, A., B. J. KenNedY und C. J. Watson, Metabolism, Baltimore 13, 391 (1964). 116. Monckton Copeman, P. W., D. J. Cripps und R. Summerly, Brit. med. J. 1966/I, 461. - 117. Koskelo, P., A. Eisalo und I. Torvonen, Brit. med. J. 1966/I, 652. - 118. Matiar-VahaR, H. und E. Lungershausen, Dtsch. Med. Wschr. 92, 1809 (1967). 119. De Marreis, F. und C. Rimingron, Lancet, London 1962/I, 1332. - 120. Shemis, D., in: 1. c. 44, S. 4. - 121. Doss, M., Z. Naturforsch. 24b, 143 (1969). - 122. Doss, M., Klin. Wschr. 47, 228 (1969). - 123. Remmer, H., Proc. Europ. Soc. Study of Drug Toxic., Vol. IV, Cambridge (1964). - 124. Remmer, H. und H. J. Merker, Science, Washington 142, 1657 (1963). - 125. Cowger, M. L., R. P. Labbe und M. Sewell, Arch. Biochem. Biophysics 101, 96 (1962). - 126. Orrentus, S. und J. L. E. Ericsson, J. Cell Biol. 28, 181 (1966). - 127. Conney, A. H., A. G. Gilman, J. biol. Chemistry 238, 3682 (1963). - 128. Orrenius, S., J. Cell Biol. 26, 725 (1965). - 129. Estabrook, R. W., D. Y. CoOper und O. Rosenthal, Biochem. Z. 338, 741 (1963). - 130. Brodie, B. B., in: Ciba foundation symposium on enzymes and drug action, ed. by J. L. Mongar und A. V. S. de Reuck, J. \& A. Churchill LTD, London (1962), S. 317. - 131. Klingenberg, M., Arch. Biochem. Biophysics 75, 376 (1958). - 132. ReMmer, H. und H. J. Merker, Ann. N. Y. Acad. Sci. 123, 79 (1965). - 133. StrittMATter, P., in: Biological oxidations, ed. by T. P. Singer, Interscience Publishers (1968) S. 171. - 134. Omura, T. und R. Sato, J. biol. Chemistry 239, 2370 (1964). - 135. KNox, W. E., in: 1. c. 130, S. 245. - 136. MAson, H. S., Mechanisms of oxygen metabolism, Adv. Enzymol. 19, 79 (1957). - 137. NArisawa, K. und G. KIKUCHI, Biochim. biophysica Acta, Amsterdam 99, 580 (1965). 138. Narisawa, $K$. und G. Kikuchi, Biochim. biophysica Acta, Amsterdam 123, 596 (1966). - 139. KAdENBACH, B., Biochim. biophysica Acta, Amsterdam 138, 651 (1967). - 140. Penniall, R. und N. DAvidian, FEBS Letters 1, 38 (1968).

Dr. M. Doss $355 \mathrm{Marburg} / \mathrm{Lahn}$ Pilgrimstcin 2 